This item was submitted to Loughborough's Research Repository by the author.

Items in Figshare are protected by copyright, with all rights reserved, unless otherwise indicated.

\title{
Reconfigurable and transportable container-integrated production system
}

PLEASE CITE THE PUBLISHED VERSION

https://doi.org/10.1016/j.rcim.2018.02.008

PUBLISHER

(C) Elsevier

VERSION

AM (Accepted Manuscript)

\section{PUBLISHER STATEMENT}

This work is made available according to the conditions of the Creative Commons Attribution-NonCommercialNoDerivatives 4.0 International (CC BY-NC-ND 4.0) licence. Full details of this licence are available at: https://creativecommons.org/licenses/by-nc-nd/4.0/

\section{LICENCE}

CC BY-NC-ND 4.0

\section{REPOSITORY RECORD}

Adamietz, Raphael, Tim Giesen, Pablo Mayer, Andrew Johnson, Richard Bibb, and Christian Seifarth. 2018. "Reconfigurable and Transportable Container-integrated Production System". Loughborough University. https://hdl.handle.net/2134/32086. 


\title{
Reconfigurable and transportable container-integrated production system
}

\author{
Raphael Adamietz ${ }^{1}$, Tim Giesen ${ }^{1}$, Pablo Mayer ${ }^{1}$, Andrew Johnson ${ }^{2}$, Richard Bibb ${ }^{2}$, Christian \\ Seifarth \\ ${ }^{1}$ Fraunhofer Institute for Manufacturing Engineering and Automation IPA, Stuttgart, Germany \\ ${ }^{2}$ Loughborough Design School, Loughborough University, Leicestershire, UK
}

Corresponding author: Raphael Adamietz

Nobelstr. 12

70569 Stuttgart, Germany

raphael.adamietz@ipa.fraunhofer.de

+497119701138

\section{Abstract}

In this paper, the concept and the prototype realization of a novel reconfigurable small-footprint manufacturing system in a transportable container is presented. The containerized format enables transportation of the system to provide on-site manufacturing, enabling the benefits of localized service delivery without duplication of equipment at multiple locations.

Three industrial product use cases with varying manufacturing and performance requirements were analyzed. All of the use cases demanded highly customized products with high quality in low production volumes. Based on their requirements, a general system specification was derived and used to develop a concept for the container-integrated factory.

A reconfigurable, modular manufacturing system is integral to the overall container concept. Production equipment was integrated in the form of interchangeable process modules, which can be quickly connected by standard utility supply and control interfaces. A modular and self-configuring control system provides assisted production workflow programming, while a modular process chain combining Additive Manufacturing, milling, precision assembly and cleaning processes has been developed.

A prototype of the container-integrated factory with reconfigurable process modules and control system has been established, with full functionality and feasibility of the system demonstrated.

\section{Introduction}

Time is a valuable resource in the management of production processes and in this context its use needs to be optimized. Production management methods such as lean manufacturing focus on the elimination

of time spent on non-value-added processes, whilst focusing on the performance of value added 
processes [1]. Quick Response Manufacturing focuses on the optimization of lead times in order to obtain a competitive advantage. If the principles are applied correctly, product quality and production costs can be optimized and the competitiveness of the company can be improved [2].

Shipping often has a strong impact on total lead-time. It may take several days, often weeks, for a product to arrive at its destination, especially to remote locations. If a product is shipped across international borders, further delays may arise as a result of customs processing. In consequence, to reduce lead times, shipping and customs processing times are subject for optimization. [3]

Lead times become particularly important with custom-made products as they typically cannot be preproduced and stored until demanded [2,3]. This is particularly the case for many medical products, such as orthotics, prosthetics or surgical aids. Especially for the latter case, the lead-time may be critical, e.g. if a patient (resp. customer) is awaiting surgery.

One way to reduce shipping times is to move production closer to the customer. This way shipping times and thus, lead times can be minimized.

In order to improve the lead times for custom products, this work aimed to realize a manufacturing system that:

$>$ can be rapidly (re-)configured,

$>$ can be transported and set up at the location of need in a rapid and simple way

$>$ can produce customized products close to the customer at the required quality whilst minimizing lead times

To provide the desired mobility, the system must be compact and easily transportable it needs to be integrated within a single enclosed unit. In addition, established vehicles should be able to transport the system, therefore a standard container was selected as the production system platform.

As medical products were identified to have the highest requirements in the manufacturing portfolio special focus was paid to the precise control of the process conditions, i.e. particulates, biological and chemical contamination.

This paper describes how a comprehensive concept for a containerized mobile manufacturing system was developed, physically realized and demonstrated.

\subsection{Decentralized Production}

Centralized production is replaced more and more by decentralized production and top-down methods by bottom-up synthesis [4, 5]. The adoption of production networks and distributed production is essential to the increase of competition and market globalization of manufacturing companies as well as Small and Medium Enterprise [6]. Matt et al. describe several approaches to cope with the challenges imposed by the changing production landscape [5]. Mobile, non-location-bound factories are identified as possible approach to realize geographically distributed production networks [5]. Such mobile production facilities require a high degree of flexibility in various dimensions, as well as the capability to be reconfigured in order to adapt the flexibility corridor to the continuously changing requirements of the market $[5,7]$. 
The availability of such mobile production facilities allows the setup of geographically distributed networks, connected and orchestrated by cloud services. These enable in turn cloud-based design of products and local manufacturing [8]. In this context, distributed networks of additive manufacturing facilities are discussed, with their high degree of process and design flexibility [9].

\subsection{Reconfigurable Manufacturing Systems}

A widely followed approach to rapid reconfiguration and continuous adaption are Reconfigurable Manufacturing Systems (RMS) [10]. RMS are designed at the outset for rapid change in structure, as well as in hardware and software components, in order to quickly adjust production capacity and functionality within a part family in response to sudden changes in market or regulatory requirements [10]. They are marked by three main characteristics namely dedicated flexibility, convertibility and scalability, and three supporting characteristics such as modularity, integrability, and diagnosability) [11].

The successful implementation of RMS requires autonomous and intelligent components on different granularity levels, which are to be accommodated within the formed superordinate system [12]. The intelligent components need to be supervised and orchestrated in order to efficiently and reliably achieve the system's goals $[13,14]$. Additionally the system needs to provide an appropriate level of responsiveness in order react to changes from market, product and available resources $[15,16]$.

\subsection{State-of-the-Art}

Miniaturized factories can be classified principally into transportable and stationary systems. A classification of transportable factories is provided by Fox, referring to three different types of moveable factories. The first type comprises mobile factories fitted inside a van or mounted on the back of a truck. A second type is mobile factories that can comprise one or several shipping container units. A third type is moveable factories consisting of a number of volumetric elements significantly larger than a container. [17]

Postawa et al. proposed a containerized concept with an integrated mini-factory for the production of cocoa paste [18]. Um et al. developed a prototype 20' container factory for the growth of plants and vegetables [19]. Both systems are mounted on trucks, are therefore highly mobile and can be classified to type I. The US Special Operations Command (SOCOM) have realized a container-integrated system to create mobile workshops by integrating CNC machining and 3D laser-sintering systems into standard 20' containers [20,21] to produce spare parts in the field in order to reduce lead times [21]. This system may serve as an example for a type II system. An example for Type III system is a plant factory, consisting of a number of connected containers, allowing for the farming of plant under controlled conditions [22].

Miniaturized production lines are also often described as Desktop Factories [23]. One example, the TUT Microfactory is based on miniaturized production units (modules) for small products [24]. Each of the modules is equipped with standard interfaces which can be combined in order to realize small production lines. Miniaturized desktop factories have typically a small footprint, are reconfigurable and could be principally integrated into a container. For example, Jackson et al. have proposed a concept for a container-integrable manufacturing equipment [25]. 
In summary a number of containerized or mobile manufacturing solutions already exist. Also miniaturized production systems are available. However, a comprehensive solution, integrating both concepts and satisfying the prior determined requirements does not yet exist.

\subsection{Motivation: Reduction of lead times for customized products}

Typically, a product is manufactured at a central location. Once an order has been placed, the customized product is engineered and manufactured. An opportunity existed to optimize these processes and reduce lead times. Following manufacture, the produced part(s) are sent for delivery to the customer, with shipping taking anywhere between several days to weeks to reach their destination. Problems often also arise at border customs or when different service providers have to cooperate along the supply chain

While standard products (not custom-made) may be stocked in number close to the location of need, highly individual, customer-dependent customized products cannot be stocked locally prior to demand.

However, if manufacturing is performed within close proximity to the customer, packaging and shipping can be better controlled, the distances travelled can be minimized and customs matters can be shifted into the earlier phases of the value chain where time is less crucial (i.e. raw materials). A comparison of both scenarios is shown in Figure 1.

Within a localized production scenario for example, a custom surgical aid may be manufactured close to a hospital and becomes available within a couple of hours. Production of custom prosthetics or orthotics often requires several fittings and adaptions. For example in the UK, it may often take several weeks and multiple sessions until a patient's orthosis is properly fitted. By moving the manufacturing system closer to the customer, overall lead-time could be significantly reduced.

\begin{tabular}{|c|c|c|c|}
\hline \multicolumn{4}{|c|}{ Centralized Production } \\
\hline $\begin{array}{l}\text { Order } \\
\text { Entry }\end{array}$ & $\begin{array}{c}\text { Engi- } \\
\text { neering }\end{array}$ & $\begin{array}{c}\text { Manu- } \\
\text { facturing }\end{array}$ & $\begin{array}{l}\text { Packaging and } \\
\text { Shipping }\end{array}$ \\
\hline \multicolumn{3}{|c|}{ 1-4 Days } & 3-14 Days \\
\hline \multicolumn{4}{|c|}{ Decentralized Production } \\
\hline \multirow[t]{2}{*}{$\begin{array}{l}\text { Order } \\
\text { Entry* }\end{array}$} & $\begin{array}{c}\text { Engi- } \\
\text { neering }\end{array}$ & $\begin{array}{c}\text { Manu- } \\
\text { facturing }\end{array}$ & $\begin{array}{c}\text { Packaging } \\
\text { and Shipping }\end{array}$ \\
\hline & 1-4 Day & & 1-2 Days \\
\hline
\end{tabular}

Figure 1: Envisaged lead time reduction by local production units

\subsection{Objectives}

The objective of this work was to realize a system that provides the capability to manufacture customized products close to the point of need at the required time. To realize this, the system must be easily transportable with minimal effort required for its relocation. 
Rather than developing the system for a specific application, a high degree of adaptability was projected and implemented. This corresponds to the definition of a flexible system realized by a reconfigurable, modular production system. In order to cope with changing operational requirements that may exceed the initial flexibility provided, the system should be designed to enable it to continuously evolve [26] or facilitate a sufficient degree of changeability [27]. Once the system is deployed at a remote location, it must provide the required infrastructure to perform the desired production processes. The process conditions must remain within specified limits regardless of the location of operation. As the availability of expert personnel at remote locations may be limited, the control of the equipment and the associated software must be as user-friendly as possible and employ a high degree of automation and assistance.

A workflow for the engineering, pre-processing and manufacturing of customized parts is also required. The workflow management system should also provide a user-friendly interface and a high degree of automation.

The manufacturing processes are required to facilitate the production of customized products. These processes should provide a high level of flexibility, while keeping a sufficient degree of reliability and availability. In summary, the following properties were required:

$>$ Rapid configuration and deployment

$>$ Easy transportation to the point of need

$>$ Reliable operation at remote locations

$>$ Production of highly individualized products

The opportunities enabled by future factory features (localization, adaptation, and customization) will also allow the implementation of a consumer-centric business model in a decentralized supply chain [28]. While a transportable and reconfigurable production system would allow the local availability of a manufacturer's portfolio, the conventional business model of 'the producer produces for the consumer' will be progressed. As such, the consumer may take over the production activities of the manufacturer for customization purposes. The idea of a consumer acting as a producer has previously been highlighted by Alvin Toffler in $1980[28,29]$ suggesting, that 'prosumers' become more important while industrial countries transform from the Industrial Age to the Information Age. Nowadays, the term 'prosumer' is widely used for energy harvesting, consuming and suppling owners of renewable energy systems [30]. In the context of this work, the presumption relates to involving individuals within the design and production of goods that they consume locally [31, 32].

To address these challenges within the new production system, cyber-physical components will enable the reconfigurability and usability of the system, therefore maturing the general concept into a cyberphysical production system (CPPS). CPPSs can be seen as the continued development of the fractal factory [33]. In short, the fractal factory is defined by several production fractals in which independent manufacturing units communicate with each other allowing flexible workflows [34, 35]. CPPSs combine the features of Human-Machine-Interaction, Machine-to-Machine (M2M) communication, connectivity onto platforms and digital services and decentralized decision-making for production purposes [36]. Among others, the key features of CPPSs are the economic manufacturing of customized products, comprehensive process optimization across locations, increased responsiveness and truly individual work piece-related monitoring and documentation. Therefore, the following objectives were established: 
A reconfigurable process chain using interchangeable process modules

$>$ A unified mechanical, electrical and informational platform for simplified transportation and installation

$>$ A Human-Machine-Interface suitable for prosumer interaction

$>$ Self-describing equipment for background process configuration, monitoring and documentation

\section{Materials and Methods}

\subsection{Approach}

The development phase was split into three stages starting with a comprehensive analysis of the three use cases. Thereafter, the most significant and important requirements as well as the most challenging features for the manufacturing processes were combined to generate a common production scenario. These requirements were used to design and configure the first mini-factory and its capabilities during the development phase.

For the conception of the mobile manufacturing system, a top-down approach was selected as shown in Figure 2.

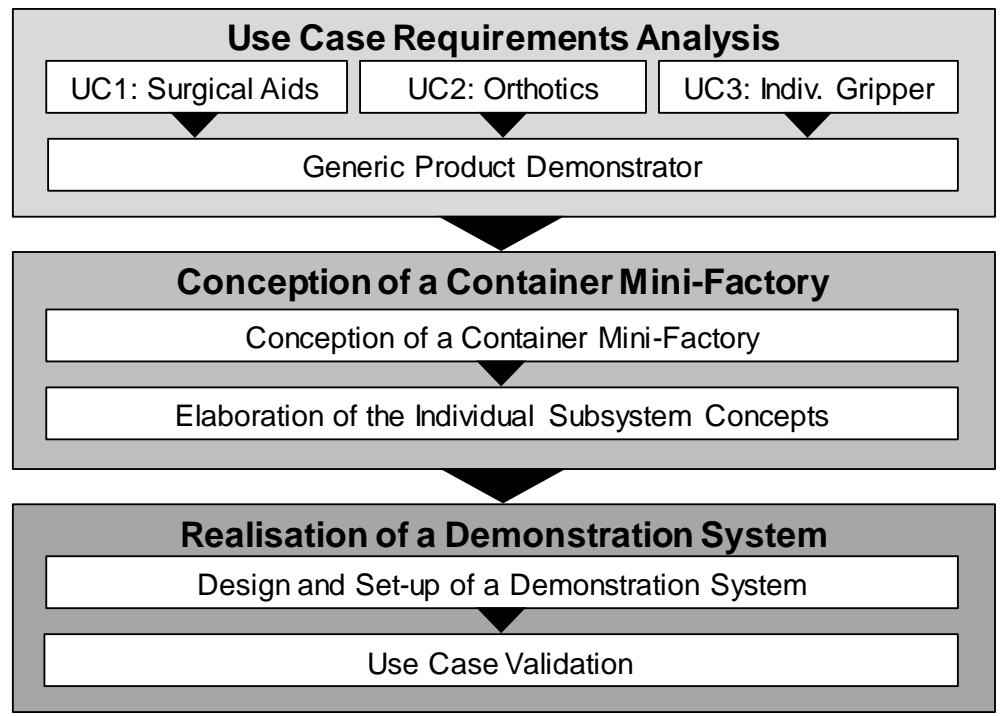

Figure 2: Methodological Approach

The conception of a container-integrated production system and the elaboration of the individual subsystems followed analysis of the system requirements. Within this stage, the task was to align the individual processing needs with the limited space by planning and drafting a common platform for the production system. The single sub-systems include the processing equipment along with the media infrastructure, the equipment for a defined environment, the mechanical platform as well as a holistic control system and a user-machine interface. 
Finally, realization and demonstration focused on the detail design of all sub-systems and their setup. The configuration and installation of all components for the demonstration container was finished before testing validated the production system by manufacturing customized parts.

\subsection{Use Case Requirement Analysis}

An analysis of the three representative use case scenarios was performed. These comprised of manufacturing of custom surgical products, customized orthotics and customized industrial gripping systems. An overview of the use case requirements is presented in Figure 3.

Within all three use cases an opportunity existed to minimize lead times significantly. The required production volumes ranged between 5 units and 20 units daily for all use cases., which corresponds to low volumes according to the classification by Thoben [37]. All three products required high levels of individualization, particularly regarding the three-dimensional shape of the products. For the medical use cases, product quality was critical and needed to be controlled. Process conditions have the potential to affect the function of the product in all three cases and therefore also need to be controlled. A "trackand-trace" of the whole process was required for all use cases. Operation of the process equipment by prior trained personnel was also necessary. The system was required to be suitable for all three use cases, as well as future use cases that may impose similar manufacturing requirements.

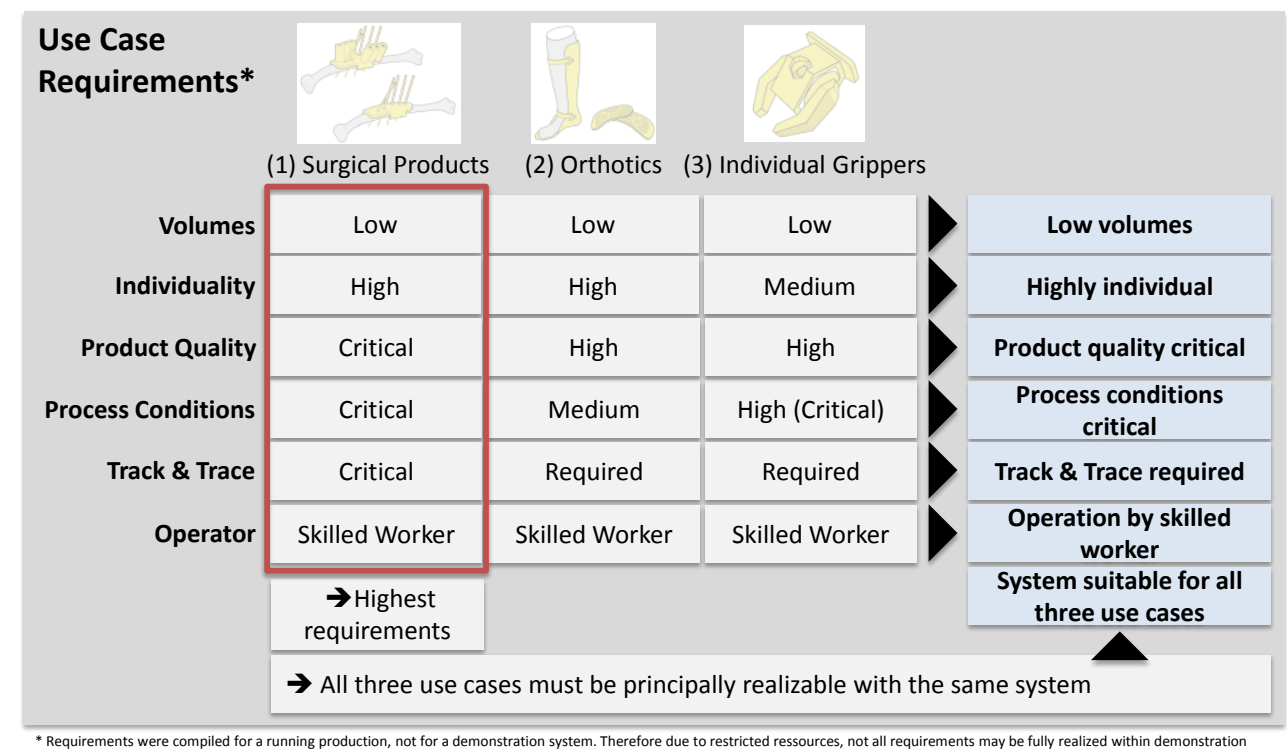

Figure 3: Use Case Analysis

A demonstration part was developed that combined the most important features of all three use cases. Measuring $62.5 \mathrm{~mm} \times 47.5 \mathrm{~mm} \times 20 \mathrm{~mm}$, it was established to incorporate a series of design and engineering features within a single component - as shown in Figure 4. 


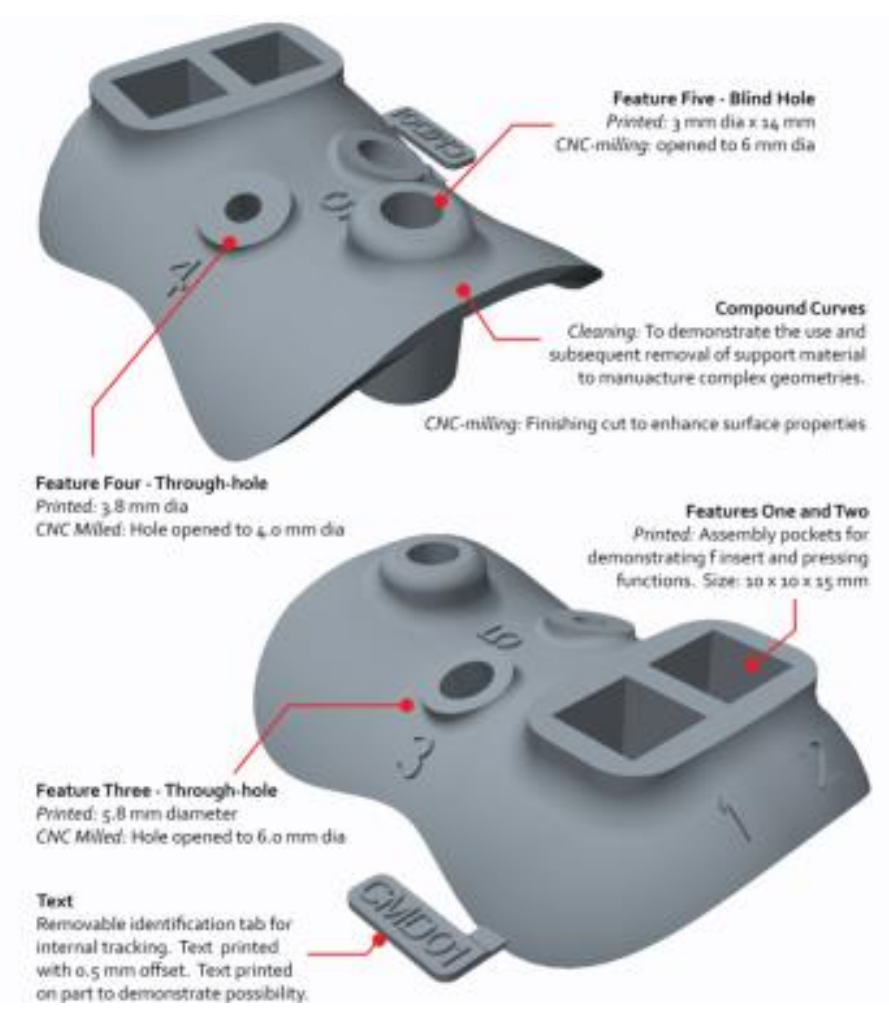

Figure 4: Integrating all use case requirements: demonstration custom part

The primary feature of the demonstration component is its compound curved surface. Its inclusion aimed to demonstrate the 3D printing of appropriate complex forms encountered in customized products; especially medical devices design to fit human anatomy. The test piece would also require support structures during its manufacture enabling testing of support materials and their subsequent removal. Features 1 and 2 as shown include two $10 \times 10 \times 15 \mathrm{~mm}$ pockets to examine the inserting, pressing and encapsulation that might be used in assembly processes. The demonstrator component also features two through-holes on the curved surface as indicated by features 3 and 4 as well as a blind hole as indicated by feature 5 . These features were intended to examine how 3D printed features could be finished to specification using CNC-milling. A further feature of the demonstration component is a breakable identification tab. The purpose of this tab is to track the manufactured component through the production processes. It can be easily removed prior to final packaging. This tag can feature 3D printed text.

\section{Conception of the container-integrated production system}

To find a suitable production process for integration within the containerized mini-factory, state of the art planning systems and production modes were assessed in relation to defined boundaries. The classification of the container-integrated production system assisted in the alignment of subsystems during the development of a common platform.

The conception of the container architecture began with its classification according to known production systems found in the literature. Although a new production system is envisaged, the classification of the 
system helped to align the subsystems and to focus on the most critical parts of the reconfigurable and mobile mini-production facility. It was important to consider the general structure of today's production planning and control systems when setting the boundaries of the system. Figure 5 depicts the general process flow of a standard production system and explains the theory of the envisaged containerized mini-production system.

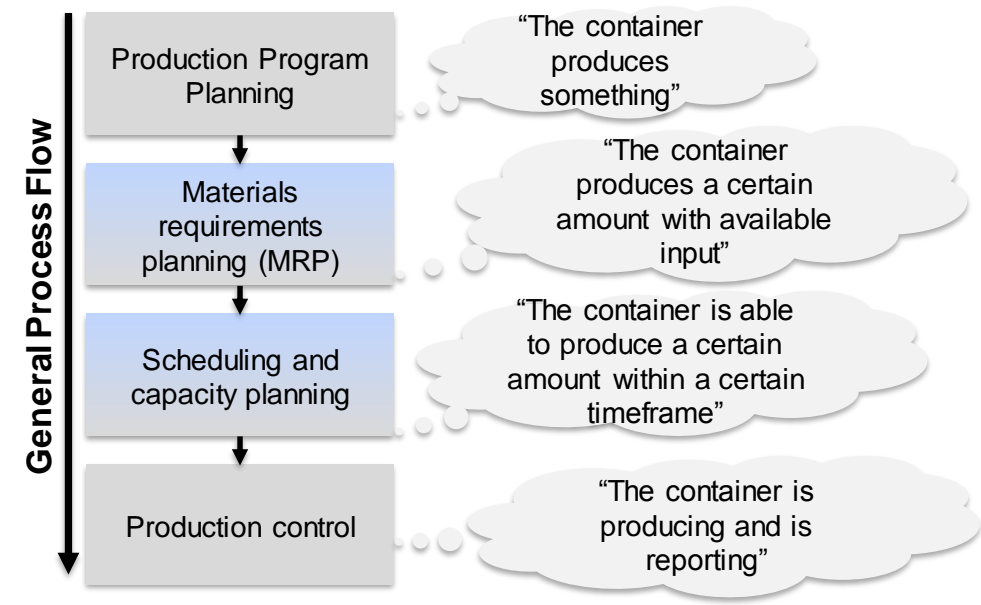

Figure 5: Production planning and control system theory.

The container-integrated production concept addresses a dedicated task for each planning step in the course of its general process flow. As a result, the boundaries of the considered production system are clearly derived in the next step of the system's conceptual design. The assignment of functions of the subsystems and the obligatory scope of the production system in the context of this project are outlined.

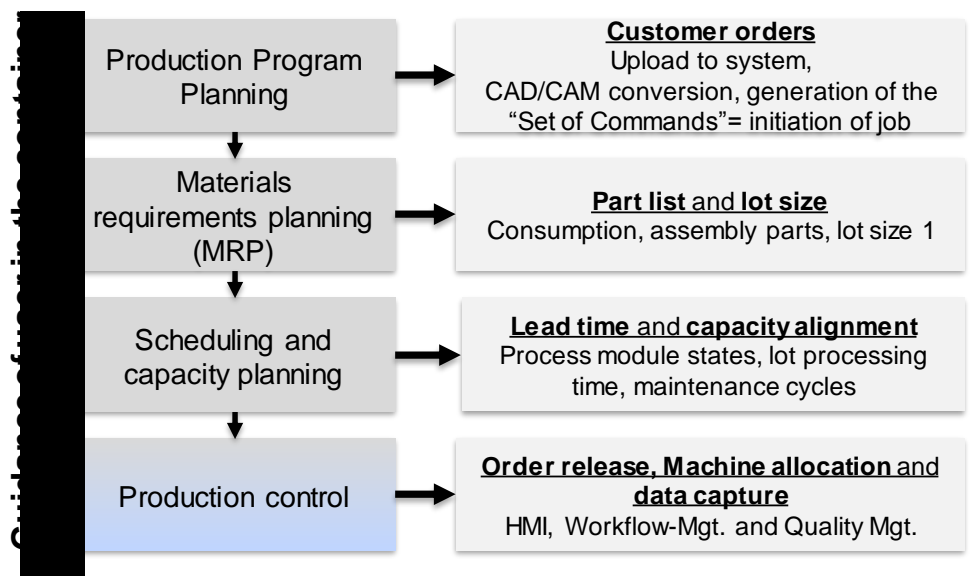

Figure 6: Steps of the production and the corresponding system boundaries.

The production program is represented by the instant request of required parts by the prosumer. Focus was then paid to technical realization via the container-integrated production system. Customer orders are uploaded and are converted into a machine processable language, called a "Set of Commands". This initiates the overall production, the job is launched and the mini-production system can be technically prepared. State of the art production planning software can be attached externally. 
Material planning is the responsibility of the individual process module providers. Automated material order or other autonomous raw materials and consumables management was deemed out of scope at this first instance. However, material stock with respect to the production ability is required within the system. As an example, when a production job is launched there has to be sufficient material stock within each production phase. Therefore, each process module is required to calculate its own consumption rates for guaranteeing sufficient operating supplies.

Scheduling and capacity planning takes the individual job processing times as well as production system capacities into account. For the container production, scheduling and capacity planning is subject to the process module capabilities and the percentage of manual work is dependent on the produced parts. General lead times are defined by the specific use case requirements. Maintenance cycles for the system will be executed regularly, while process module maintenance may be required more often, such as the restocking of materials.

Production control in the container mini-factory and its objects are represented by the Human Machine Interface (HMI), the Workflow-Manager and the quality assurance functions. The production control integrates the subsystems into one production system. Therefore, the visualisation of the total system, the visualisation of the processing modules, the process initiation of the individual processing modules and the data capture of significant key figures for quality traceability are the most important functions of the production control. Sensitive prosumer guidance for the user-container interaction is also covered by the production control system. For the system concept, the classification towards a labour-intensive production or an equipment intensive production is balanced due to the fact the characteristic depends on how the achieved flexibility of the mini-factory could be utilized. This comes along with the classification of the production flow method: in-line production is less flexible but more efficient, while shop production has a flexible but a more inefficient production flow. Following consideration of the use case requirements, it was concluded that the realized manufacturing system should be capable of producing multiple parts at once but with a high level of customization. As a consequence, the production is single-item focused but with several similar parts - also known as batch production. Within this concept, this only applies for the Additive Manufacturing process module. Any further processing inside the mini-production will be single-part operated. The circumstance of a changing lot size within the production flow requires part buffering (centralized in the container/decentralized in the process modules). Alternatively, the disrupted continuity of the lot size will likely require the separation of parts following the Additive Manufacturing process when multiple objects could be generated in one process. Such separation was considered as a manual step, where the user/operator will need to interact with the machine.

Single-item production, the high flexibility within the process chain and the manual interaction in the production process flow are characteristics of the mini-factory concept. Therefore, the considered type of production is the "shop fabrication" as documented in in Table 1. 
Table 1: Type of production according to the system`s features.

\begin{tabular}{|l|c|c|c|}
\hline Related feature & $\begin{array}{c}\text { Shop } \\
\text { fabrication }\end{array}$ & $\begin{array}{c}\text { Batch } \\
\text { fabrication }\end{array}$ & $\begin{array}{c}\text { In-line } \\
\text { fabrication }\end{array}$ \\
\hline High product diversity & ++ & + & -- \\
\hline Small lot size & ++ & + & -- \\
\hline Automated part transfer between processes & - & - & ++ \\
\hline Similar products in average lot size & + & ++ & - \\
\hline Use Case "Surgical Aids" & ++ & + & -- \\
\hline Use Case "Orthotics" & ++ & + & -- \\
\hline Use Case "Individual Gripper" & ++ & + & - \\
\hline Fast material flow adaptation & ++ & + & - \\
\hline Independence of production steps & + & + & - \\
\hline
\end{tabular}

As previously highlighted, the intended container production system concept is based on a top-down approach. An overview of the system and its elements is presented in Figure 7.

The housing structure is provided by a technical container. A $20^{\prime}$ or comparable type container was designated as a reference for the system; the principal concept may however be adapted to other dimensions. The purpose of the container is to provide the infrastructure necessary to operate the integrated production equipment. Depending on the product (e.g. medical products) and the requirements of the production process, the environmental conditions need to be controlled and documented. A cleanliness concept was therefore an inherent part of the system. This allows for the adaption of process conditions according to principle "just as much as necessary". Control of the process conditions comprises primarily of temperature, humidity and particle contamination but it may be extended to further parameters such as biological or chemical contamination, as well as the documentation of the system's condition during processing.

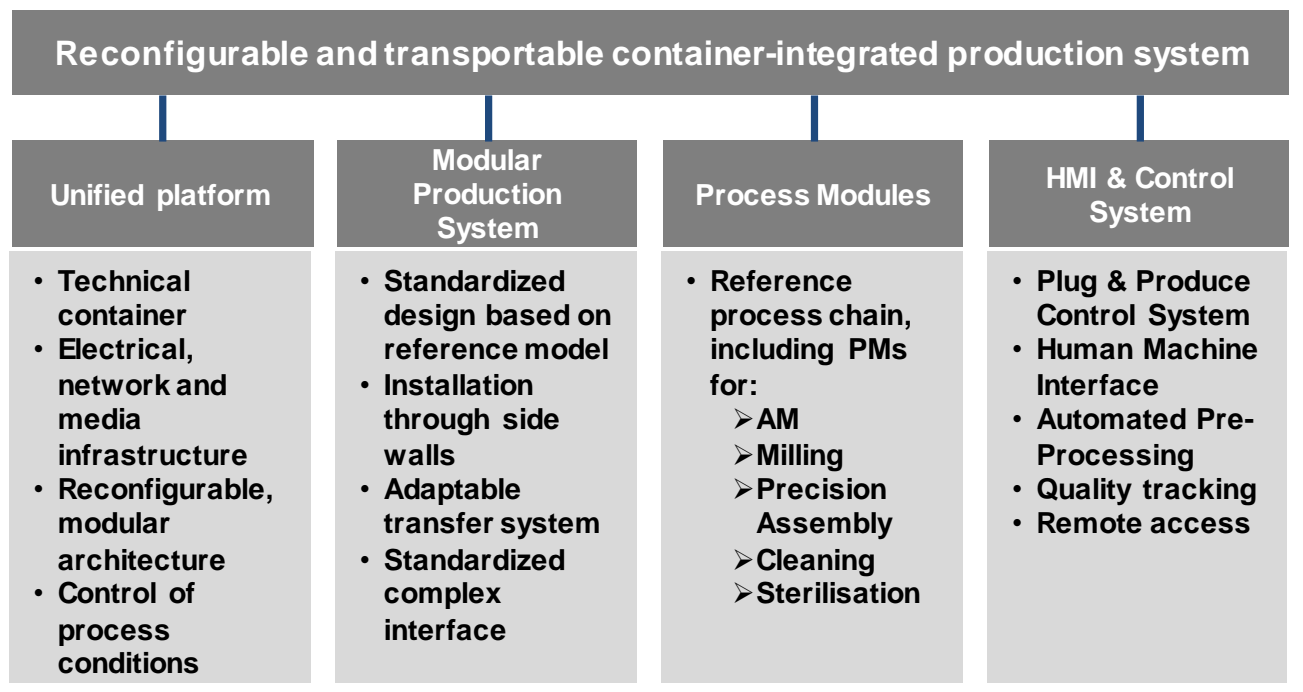

Figure 7: Overview of the system concept elements

The production system inside the container is based on a truly modular architecture. To mount the process equipment in the form of process modules (PM), the container provides a number of mechatronic receptacles with standardized interfaces. 
For the realization of the PMs, reference designs and thorough interface specifications were established. For the realization of highly customized medical products, a novel process chain was proposed, which comprises AM (3D Printing), CNC Milling, Precision Assembly, Inspection and Cleaning processes. However, depending on the envisaged service, a different set of process modules may be integrated. The production control system and human-machine-interface (HMI) supports the operator in the control and production of the customized parts.

The HMI also allows access to the production system via the Main Control including the workflow manager and the equipment's controls. Direct access to the HMI within the container is available via a front panel and there is also the facility to safely access the HMI from a remote location. The control system 's components together support a "plug \& produce" practice and configures the production system in an automated way. Processing of the individual geometrical models to machine readable manufacturing language is performed automatically via back-end software in pre-processing modules.

\subsection{Reconfigurability}

The container and the manufacturing system need to comply with the requirements identified for all four phases of the system's deployment. Additionally reuse and reconfiguration need to be considered.

Within the configuration phase the implementation of process equipment and eventually a transfer system has been performed. Therefore, the container system needs to be able to house and to mechanically support the changeable production equipment and to provide the infrastructure to operate it.

To facilitate the reconfiguration of the system, a modular production system was considered. Therefore, distinct production processes are provided in the form of process modules (PM). In this context, a process module is an autonomous production unit that provides a distinct manufacturing process [10, 38].

The overall container provides the slots/sockets for a number of PMs. Each slot provides a mechatronic supply connector that provides a safe energy supply, links to the safety circuit and connection to the container control system [38].

Consequently, to provide the supply for the production equipment, a suitable infrastructure within the container was required. This infrastructure comprises electrical and fluid circuits, as well as network infrastructure and servers for the deployment of software and control services. To operate the container, an external supply with electrical energy and other utilities, as well as network access is required.

The operation of many production processes, typically in the semiconductor or the medical industries, require the control of the manufacturing environmental conditions. This typically comprises of temperature and humidity, but also particle contamination or chemical or biological contaminants in the

air. In order to control these factors, an air conditioning and filtration system was established as part of the container concept matching the ISO 14644 class 6 cleanroom specifications. 
A schematic of the container design is shown in Figure 8. The dimensions are approximately based on the dimensions of a $20^{\prime}$ container. However, due to regulations for working rooms, the container has a minimum internal height of $2300 \mathrm{~mm}$. As an essential infrastructure component, the control cabinet housing the front panel, a server cabinet and an air conditioning system were located to one side of the container for convenient access.

The PMs can be installed within any of the six process module slots. A PM occupies at least one and may occupy up to all six slots. Each slot is equipped with a standard media supply interface. Six individual wall elements cover the slot area and they can be removed for the installation and retraction of the various PMs.

Depending on the production process and the desired throughput, a manual or automated transfer system may be beneficial. Thus, within the outlined concept, space for an automated transfer system directly in front of the process modules was reserved.

Based on the conceptual design, different configurations can be realized. Figure 9 shows three representative container configurations.

Sample Configuration 1: In this scenario, four PMs with different widths are installed. No transfer system is installed, which allows a free transfer between each PM. This set-up provides a relatively low throughput, but high flexibility. This scenario is particularly suitable for cases where the cycle times of the installed processes do not match or where a high degree of flexibility is required (e.g. shop-style production).

Sample Configuration 2: In this scenario, six PMs with identical widths are installed. Additionally, an automated transfer system is integrated. While the transportation system impairs flexibility, throughput is significantly higher than in the first example. Cycle times of the processes within this configuration should be approximately matched.

Sample Configuration 3: Instead of using all the PM slots, some space may be used to install an area within the container for purposes other than manufacturing. For example, a sales room could be installed within the container to complement the manufacturing activities enabling products to be manufactured immediately on location and on demand. 


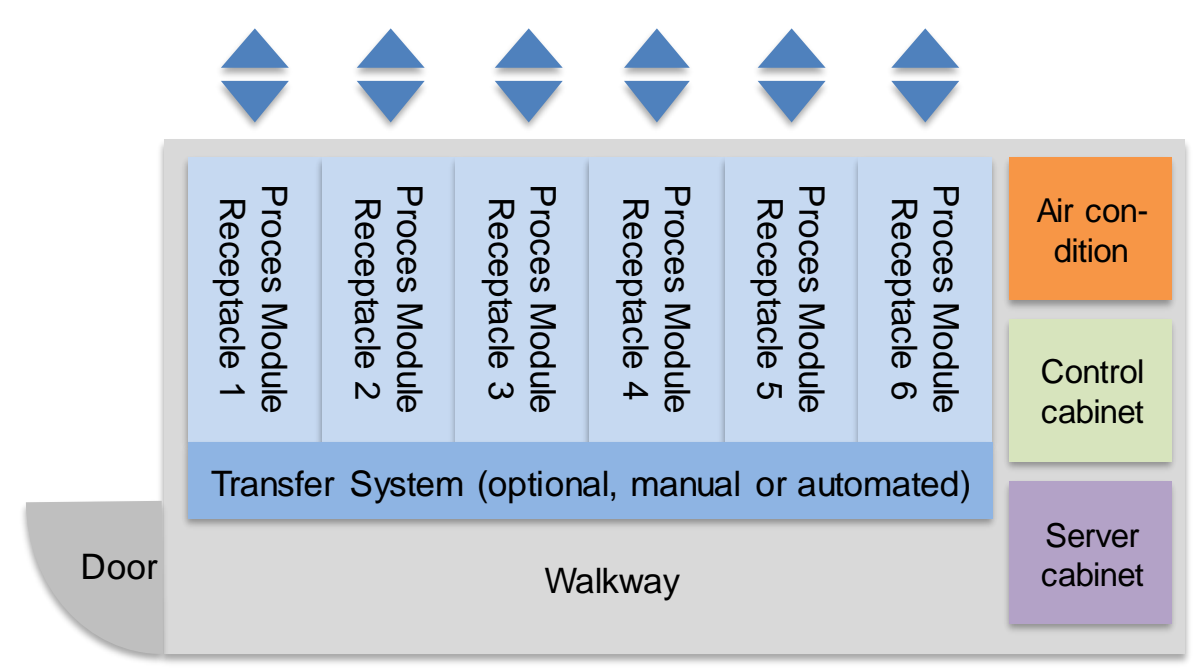

Figure 8: Container and modular manufacturing system

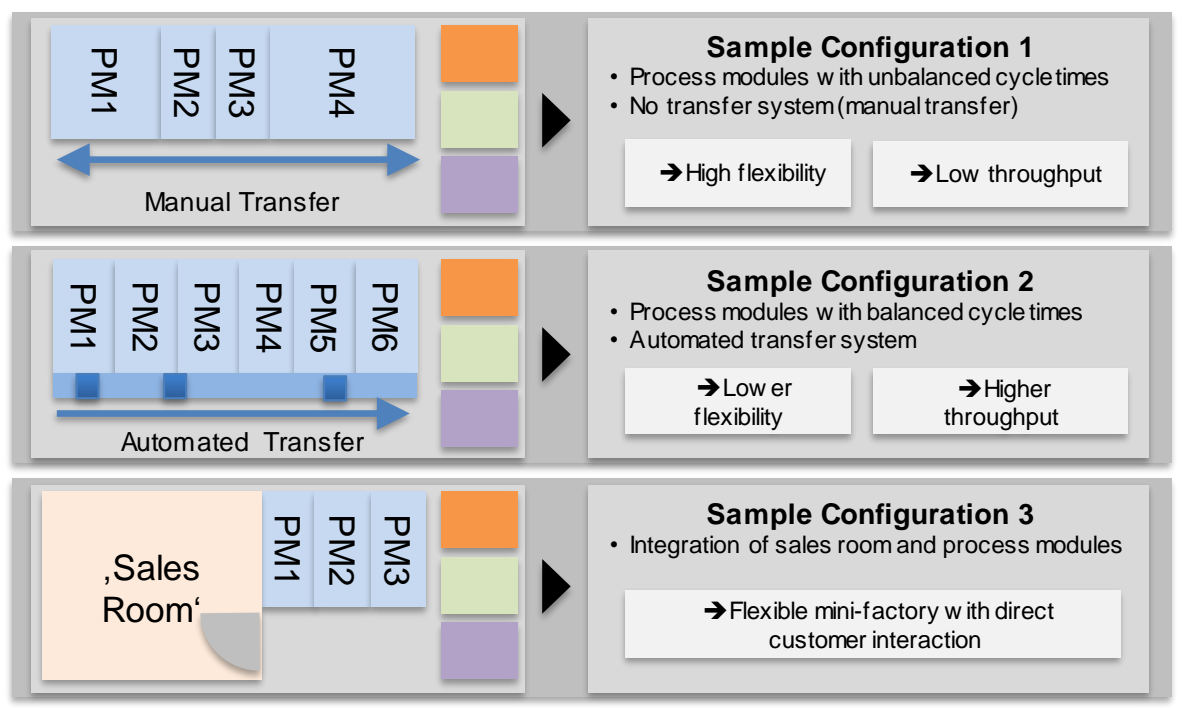

Figure 9: Representative container configurations

\subsection{Modular Control System}

As a part of the container production system, the concept of a self-adapting control system has been developed. Two motivations exist for not embedding sophisticated control intelligence such as CNC or PLC directly within the PMs: the cost reduction for the individual module and no necessity for a powerful control system (for example where the module has no complex capabilities such as part handling). As such, different levels of the PM's granularity can be implemented in the same production system. To enable a broad pool of PMs by different process owners and to enable them to provide their manufacturing service independently in any of the production systems an independent configuration mode is proposed based on self-describing PMs. Thus, the system allows performing a self-configuration of the installed modules and their capabilities. Self-adapting features and modularity of control systems have been widely researched for different applications [39-42]. Yet there has been no solution presented in the literature that combines heterogeneous processes (like additive manufacturing, precision 
assembly, cleaning, milling and sterilization) in such a compact way as required for this container-based production system.

In order to speed up the development process of a certain control configuration and to allow the development without the availability of the process hardware, a virtual commissioning approach was pursued. In this case the software ISG-virtuos was applied. Using graphical (CAD) and behavioral models (PLC programs) of the system, a virtual simulation can be performed. Furthermore, with the control hardware available, a hardware-in-the-loop simulation allows to test the control system beforehand. This approach allows a significant reduction of development and commissioning times, and reduces the dependence onto the physical availability of the process hardware. The automated control system configuration and the virtual commissioning approach within this project have been described in detail by Scheifele et al. [39, 40].

As illustrated in Figure 10, the modular control system is separated into single components that are connected via a communication system to allow a service-oriented architecture (SOA) based communication for production requests and real-time (RT) communication for hardware control tasks. The central component of the system architecture is the 'Main Control', consisting of the 'Workflow Manager' (WFM) and the 'Configuration Manager', which presents the production system to outside systems (e.g. an ERP-system or e-commerce applications) and receives the product order supplied by the non-skilled operator of the HMI. Figure 10 illustrates the related components communicating within and around the Main Control System (MCS).

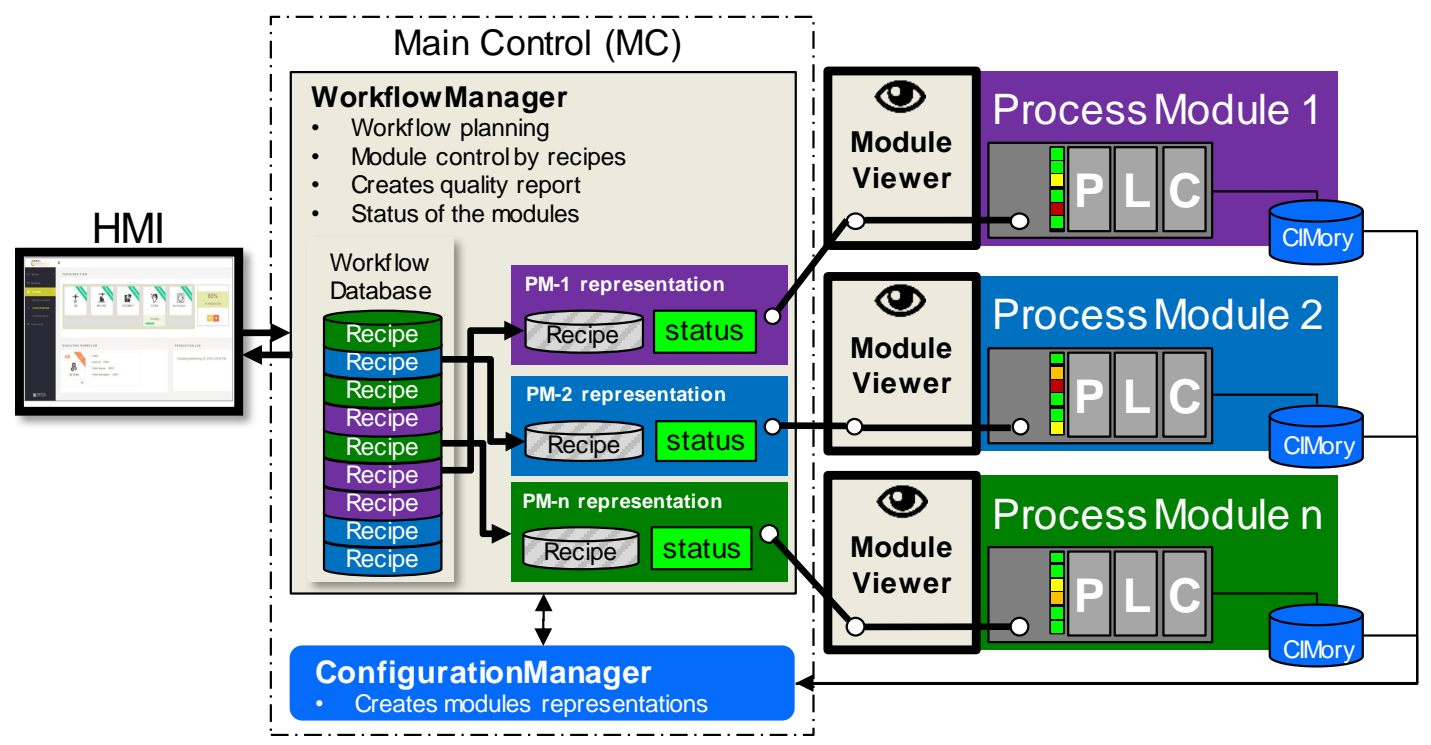

Figure 10: Self-adapting control system concept (see also [43])

The production capabilities of the MCS are defined by the installed PMs. Each PM contributes one or more production services, e.g. additive manufacturing, CNC milling, part assembly, cleaning and sterilization. The WFM handles the distribution of the production recipes based on the offered services of the PMs and establishes a suitable workflow spanning the required services of the process chain leading to the manufacture of the final product. The operation information (e.g. G-code strings) is obtained by a product-process-compiling back-end CAD/CAM system. Through the self-description 
capability of each PM and automated workflow generation, rearrangement of the production line is also feasible for non-skilled operators.

In general, a PM consists of a mechanic and kinematic structure, the inputs and outputs $(\mathrm{I} / \mathrm{O})$ for the sensors and actuators, as well as drive amplifiers (Drives). To configure the modules, the WFM asks the Configuration Manager to read each PM's Configuration and Information Memory (CIMory) while communicating during the configuration phase. The WFM itself has an interface to the Configuration Manager, which handles the configuration to set up each module's SOA service list and to compile the array of applicable workflows.

Concerning the management of the self-configuring control system, two types of PM are considered: The first type has a built in control system that is configured on delivery to the container and requires a high performance control system. The second type relies on a central control system. If, however, a PM does not have its own integrated control system, the CIMory provides this information to the Configuration Manager, which in turn uses the Central Control System (CCS) to implement a separate, software-based real-time control system for that particular PM. Two motivations exist for not embedding sophisticated control intelligence such as CNC or PLC directly within the PMs: cost reduction of the individual module or no necessity for a powerful control system (for example where the module has no complex capabilities such as part handling).

Once the PMs and the CCS-based control systems are in place, SOA communication between the WFM and each control system is established. The required information about the offered services is again obtained from the CIMory of each respective PM. Thus, this modular control system allows any common process owner to offer their production service inside the container-integrated mini-factory by using the container's unified process API and the equipment individual CIMory.

The operation of a distributed control system may lead to errors on different levels. Error resolution in distributed control systems is typically more complex than in central control systems. To ensure a reliable function at a remote location, the implementation of monitoring and diagnostic functionality is indicated. Odrey et al. propose the introduction of additional mediation and recovery functionality throughout the different hierarchy levels of the control system, enabling the capability of detecting errors and of resolving them [44]. Error detection and recovery may thus be additionally implemented to the proposed concept.

In order to be able to optimize the process performance, minimize, to track important process variables and to ensure conformity to standards, it is necessary to obtain data from different hierarchy levels. The obtained values may then be used for further calculations or control loops. For example, key performance indicators (KPIs) may be determined. The necessary variables and interfaces on all hierarchy levels are principally accessible, but are not available in a central database. The modeling of the system in the database could be performed for example with the IDEF model based on the method proposed by Hernandez-Matias [45]. 


\subsection{Human-Machine Interface}

The HMI of the container mini-factory serves as a front desk between the user and the production system. Independent of the user's authority level, the operator is able to upload the product information, configure it, set properties of the workflow and monitor the whole system. The HMI provides a number of different functions by access to the several sub-systems, including:

$>$ Status of the system and the individual PMs

$>$ Order management and execution

$>$ Selection, configuration and preparation of workflows

$>$ Access and control of process equipment

$>$ Access to quality tracking data and protocol

A schematic of the HMI system concept is depicted in Figure 11.

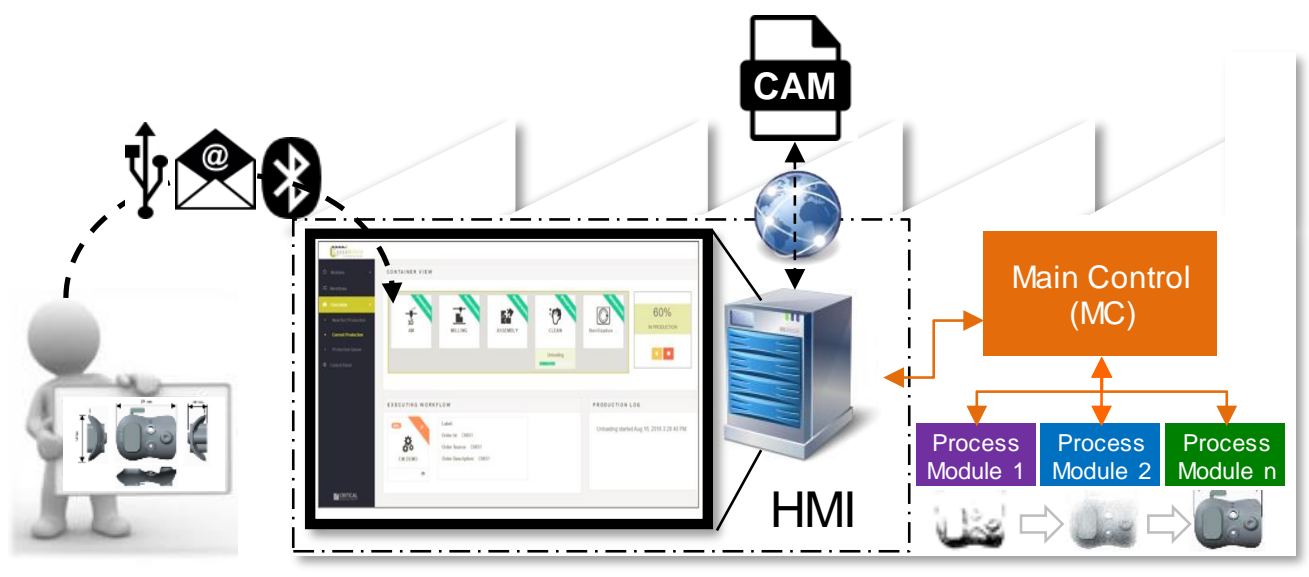

Figure 11: Concept of the prosumers' interaction via the HMI

The technical concept consists of a client-server architecture. For the client, a web client provides the operator with a usable graphical guidance that has high responsiveness and allows easy interaction, independently of the configured process chain. This client is then connected to a back-end server that provides the required information services to the client. The back-end server provides a database for storing data related not only to its internal operation but also to any required information regarding the whole system. As such, the state of the container infrastructure and the individual PMs is monitored and the capabilities of the connected sub-systems are validated.

There are two distinct paths of information between the HMI and the Main Control and two different tasks are associated to implement standard operating procedures:

$>$ The controls and the data management require reliable communication channels for requested data and issued commands. Mainly directing from the HMI to the registered PMs.

$>$ The event coordination needs a communication channel as close to real time as possible for sensitive and urgent information (e.g. critical machine status/alarm). Mainly directing from processes and inspection devices to $\mathrm{HMI}$ for a call to action and reporting. 
These abstract communication channels are also represented between the back-end server and the Workflow Manager, which allows all the required information to be collected and treated before reaching the user. There are three separate communication channels drafted for control, data and events management.

The back-end server of the $\mathrm{HMI}$ also provides access to external network services in order to use them for specific tasks, in a way similar to a plugin system, thus keeping the HMI modular and open to new additions and extensions.

Besides the communicating function, the most important task of the HMI is to report the proceedings of the production and to assign the responsibility of the manufactured product features. Especially certified process modules (e.g. ISO, GxP or NEMA conformity, etc.) will need to report its legitimacy to the HMI following the completion of the manufacturing process chain.

\subsection{Module Development and Process Chain}

A reconfigurable modular architecture was established to facilitate flexibility within the manufacturing process chain depending on the requirements of its operator. Within the established flexible mini-factory process chain, the five process modules included:

1. Additive Manufacturing (3D Printing)

2. CNC-Milling

3. Assembly

4. Cleaning

5. Sterilization

A range of Additive Manufacturing (AM) processes were initially explored for integration within the CassaMobile containerized manufacturing environment including Stereolithography, Laser Sintering, 3D Jetting, Material Extrusion (ME), and Powder Bed 3D Printing processes. Following identification of the physical constraints of the AM process module, and a series of established industrial requirements, the most suitable AM process for integration was that of Material Extrusion. The developed AM process module featured:

- A build area of $240 \times 240 \mathrm{~mm}$ within a heated chamber to assist in homogenizing environmental build temperatures.

- A dual print nozzle system for the deposition of build material appropriate for use in medical grade and FDA approved materials for end use components, as well as associated support material.

- The ability to manufacture components with a minimum tensile strength of 45 MPA and 20 MPA in the weakest direction.

- An integrated cooling system to keep critical module components such as stepper motors and inspection apparatus within optimal operating temperatures. 
As part of the AM process module, an in-process monitoring system was developed and integrated to detect and alert the system operator to identified errors within the build process - highly important for the traceability of safety critical and end-use medical components. The complete AM module is shown within Figure 12 (left).
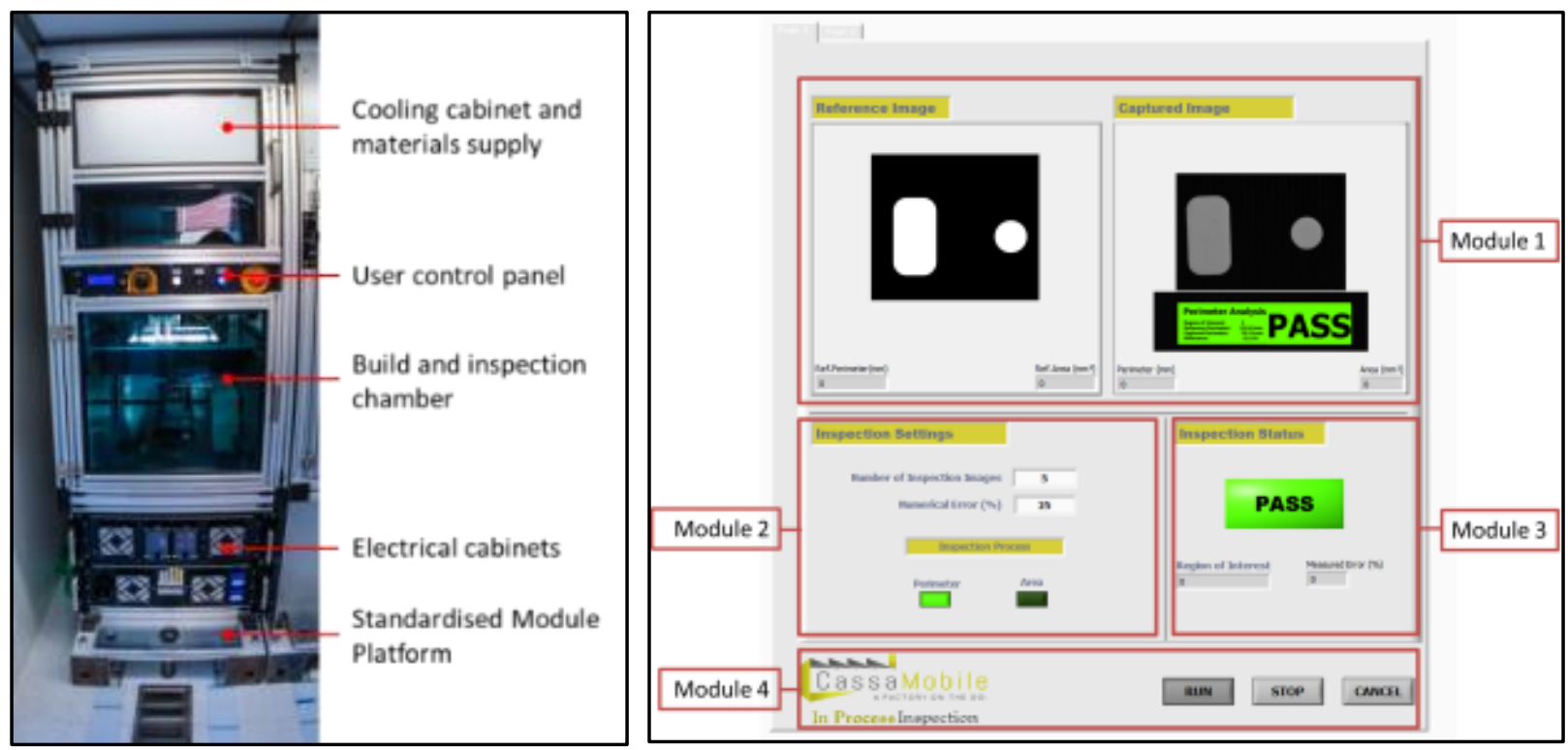

Figure 12: Additive Manufacturing module (left) and visual inspection interface (right)

To facilitate visual in-process inspection activities, the developed system featured:

- A series of four ProPhotonix Lotus line lights positioned around the circumference of the AM build area to illuminate features for process inspection, and encased within a water-cooled lighting enclosure.

- Basler acA2040-um camera with Kowa LM12HC lens fixed at a location centrally above the build platform at a height of $206 \mathrm{~mm}$ from the top printed layer, and encased within a water-cooled camera enclosure.

A dedicated in-process monitoring software solution was also developed and integrated within the wider CassaMobile control system, as shown within Figure 12 (right). The developed solution utilized crosssection PNG images generated from the original CAD file of a part intended for manufacture at a range of heights dictated by the system operator or traceability requirements. Images were then taken by the inspection system at the user specified heights during the AM build process, and compared against their respective cross-section PNG file generated using the original CAD data. Any detected errors beyond specification alert the system operator, with all captured images are stored for traceability and GMP requirements. The complete AM module was fully integrated within the wider CassaMobile control system for the preparation and monitoring of components throughout their manufacturing process.

The developed CassaMobile CNC-milling module featured a working envelope of $251 \times 261 \times 350 \mathrm{~mm}$, controlled using a Beckhoff control system, and was directly connected to the central CassaMobile control system for process monitoring purposes. Using a classical 5-axis concept, the established process module featured spindle speeds ranging between 5,000-20,000 rpm, an axis velocity of 5,000 $\mathrm{mm} / \mathrm{min}$, 
and a machining accuracy of $<0.1 \mathrm{~mm}$. Following manufacture via the AM process, parts are transferred to the CNC-Milling module and appropriately secured before performing a range of technical operations including milling, drilling, grinding, and engraving across an array of materials including polymers and metals. The developed CNC-milling module is presented within Figure 13.
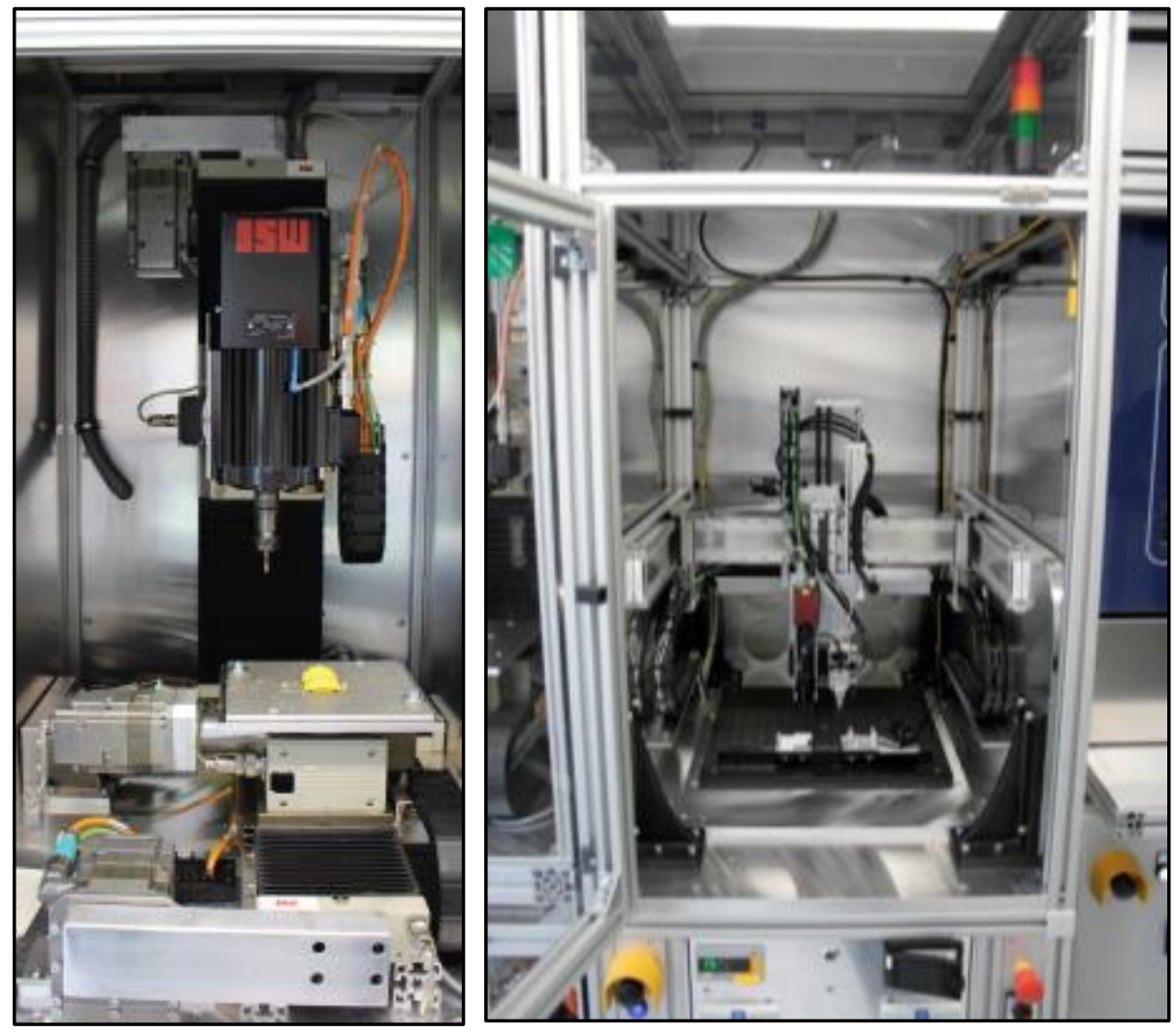

Figure 13: CNC-Milling module (left) and Assembly module (right)

The assembly module, as shown in Figure 13 (right) has a working area of $230 \times 250 \times 450 \mathrm{~mm}$ and features a Jenny Science Linax LXC linear three axis positioning system with a repeatability of $2 \mu \mathrm{m}$ per axis and combined positioning repeatability of $3.46 \mu \mathrm{m}$. To satisfy the established project and industrial requirements, the assembly module featured a range of installed tools and devices including pick and place functionality, pressing functions, and dispensing capabilities.

These tools were integrated within the CassaMobile assembly module with a view to facilitate a range of industrial requirements including the integration of electronic components within previously manufactured articles. For example, the developed system's pressing tool featured a combined gripper and pressing device up to a force of $5 \mathrm{~N}$ with a target accuracy of $\pm 0.05 \mathrm{~mm}$. In addition, its dispensing tool could be used to encapsulate electronics components such as RFID chips using a standard 3cc LuerLock time-pressure dispenser. To facilitate the accurate placement of each tool within the assembly module, an AVT Manta GigE 1600x1200px camera was installed vertically above the working area and operated using Halcon 12 vision software. The complete assembly module was controlled via the Beckhoff TwinCAT 3.1 soft PLC. 
Parts manufactured via AM, CNC, and Assembly process modules require appropriate levels of cleaning, relevant to their intended end-use environment. Cleaning operations may range from the removal of support material and machining residue, to full product sterilization. To fulfil such requirements, an ATOS instrument cleaning device (model AWD655-8) was incorporated within the CassaMobile cleaning module enabling alignment with ISO 10993 - as shown within Figure 14 (left).

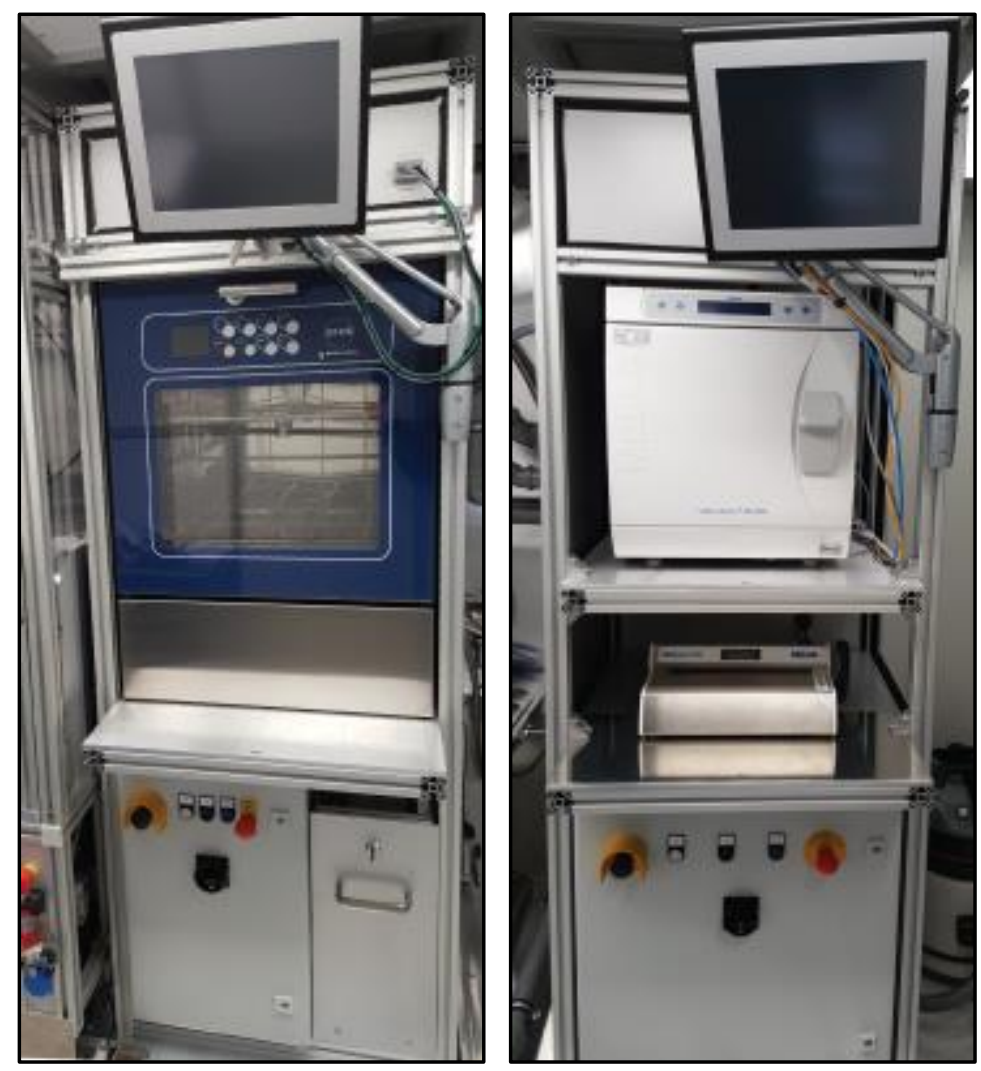

Figure 14: Cleaning module (left) and sterilization module (right)

Pre-cleaning, main cleaning and post-cleaning activities can be be performed within this single device, which was also integrated within the main CassaMobile central safety and control systems via USB and RS232 interface connections. The established apparatus also enabled programmable and high levels of traceability through the monitoring of process parameters such as temperatures, time and level of detergent or cleaning media - a requirement for medical devices.

Medical components or implants that require sterilization and packaging according to ISO 11737 can also be achieved through use of the developed CassaMobile Sterilization module. Parts can be sterilized using the integrated Melag Vacuklav 24B+ Class B steam autoclave system which features a load capacity of 22 litres - as shown within Figure 14 (right). Once cleaned, parts can be loaded for sterilization and held at a temperature of $121^{\circ} \mathrm{C}$ for 20 minutes - with the monitoring and recording of all relevant parameters such as temperature, time, and pressure to meet traceability requirements. Once sterilized, parts are appropriately sealed using the integrated and validatable Melag MELAseal 200 device.

The proposed location of each process module and the flow of manufactured parts is shown within Figure 15. 


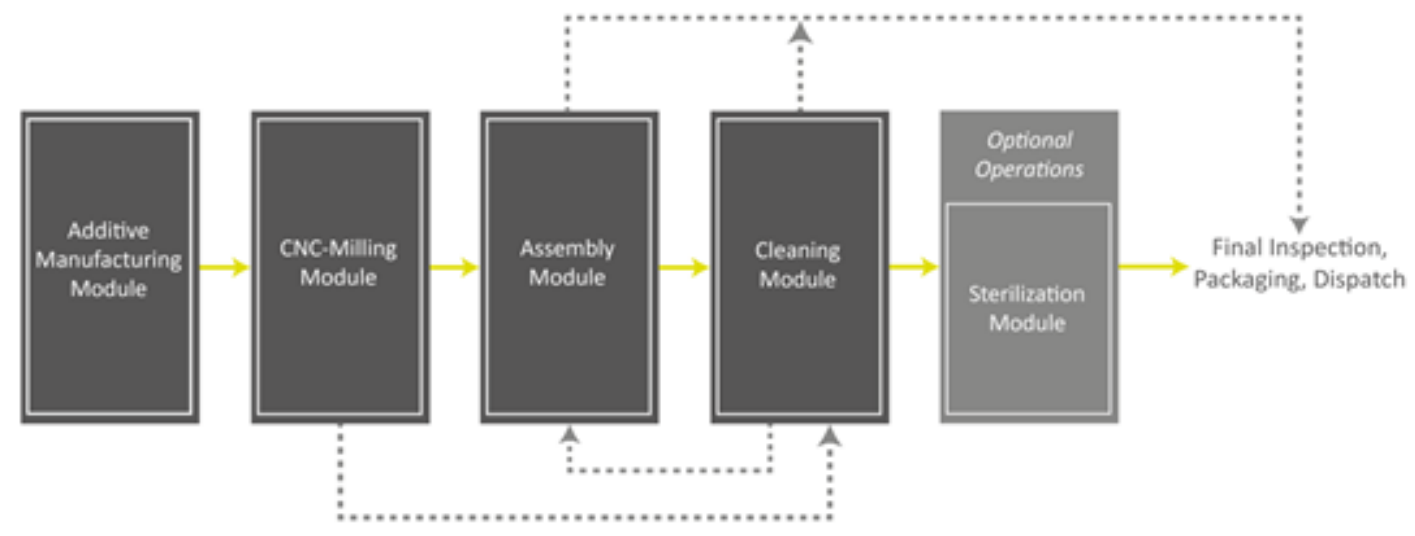

Figure 15: Process module location and process flow featuring optional module

Within the process chain shown in Figure 15, an additively manufactured component is processed through the CNC-milling, assembly, cleaning and optional sterilization modules prior to dispatch. However, opportunities also exist for the process chain of manufactured components to be modified. For example, following AM and CNC-milling operations, there may be no need for parts to enter the assembly module and therefore can progress to the cleaning and sterilization phases. Alternatively, if part sterilization is not required these modules could be replaced with multiple time intensive process modules, as shown within Figure 16.

The use of a modular system provides a level of 'future proofing' where individual modules can be updated or replaced with alternative technologies depending on the requirements of its operator.
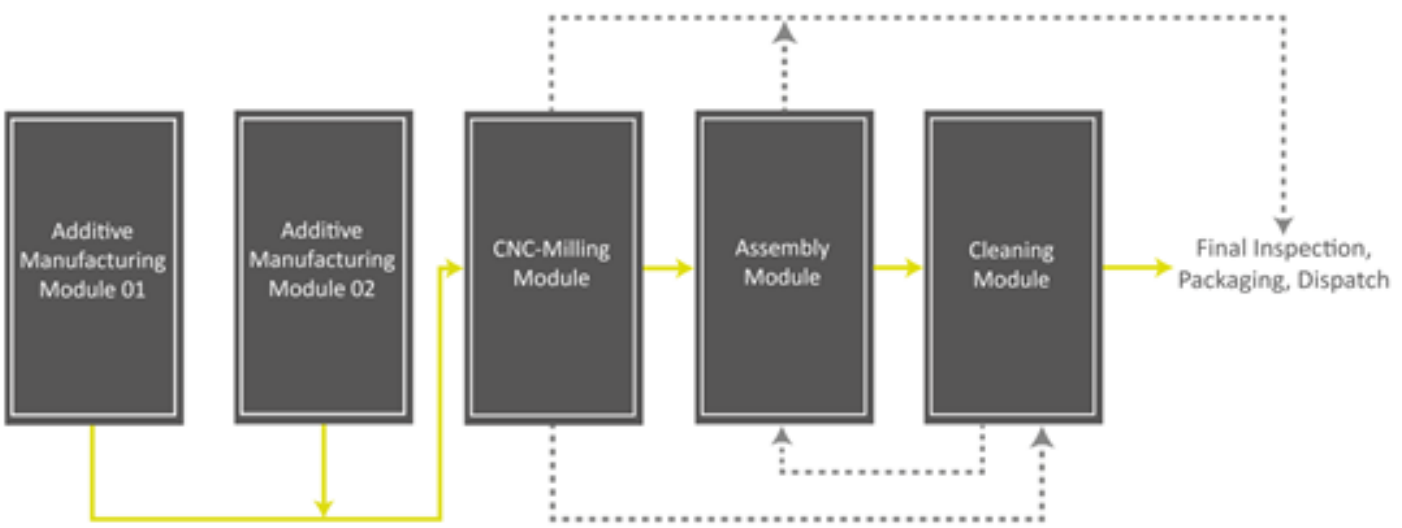

Figure 16: Process flow featuring multiple manufacturing modules

\subsection{Cleanliness Concept}

To avoid contamination with particles or other air-born contamination, an air filtration system was established within the container concept. As cleanliness is a cost-factor, the measures are limited to those necessary and not all that might be possible. Vertically above each PM slot, a fan-filter unit (FFU) is 
fitted. Each of the FFUs can be adapted to the individual process and equipment in the process module slot. Additionally, curtains may be fitted to separate areas with varying cleanliness levels/requirements.

Within the cleanliness concept, air circulates from the top of the process area, through the opposite side wall of the container, over the ceiling, and back to the FFU - as shown within Figure 17. Additionally a small portion of external fresh air is continuously fed into the system prior to the FFU.

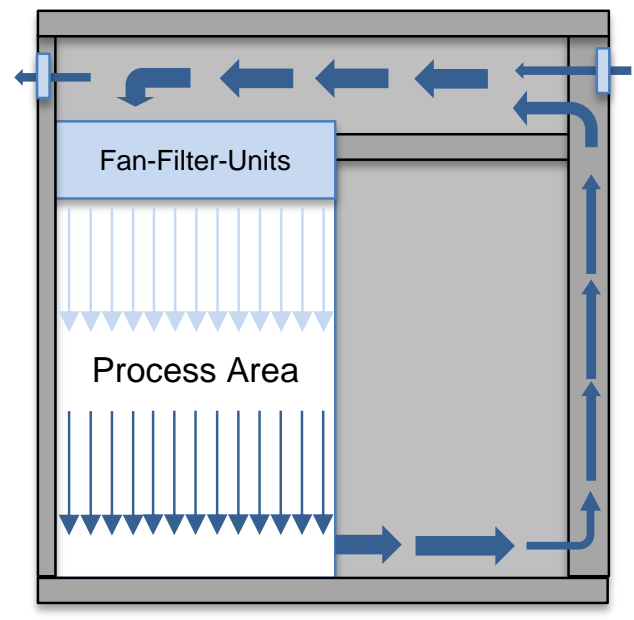

Figure 17: Air filtering concept enables ISO 14644 class 6 condition in process area

To realize the cleanliness concept, a number of measures needed to be implemented either during configuration or during operation of the production system [46], these include:

$>$ PMs needed to be separated into zones with different cleanliness levels, by curtains or air locks

$>$ Optimization of the air flow within the PM and transfer system (if applicable)

$>$ Protection from contamination by special transport and storage boxes (if applicable)

$>$ Recurrent training of personnel and determination of rules for personnel (e.g. clothing, shoes, head and mouth covers, gloves, etc.) would be required.

$>$ Continuous monitoring and documentation of relevant process conditions

The process equipment must comply with the set requirements in order to achieve the desired cleanliness level. Particularly for higher cleanliness levels, optimization of the airflow, materials or equipment (e.g. actuators) may be indicated. [47]

\section{Demonstration System}

\subsection{Realization of the Prototype System}

In order to demonstrate the feasibility and to validate the concept, a prototype of the containerintegrated production system has been realized. Figure 18 shows the configuration of the production system (integration of PM) and the finished and enclosed container mini-factory. 

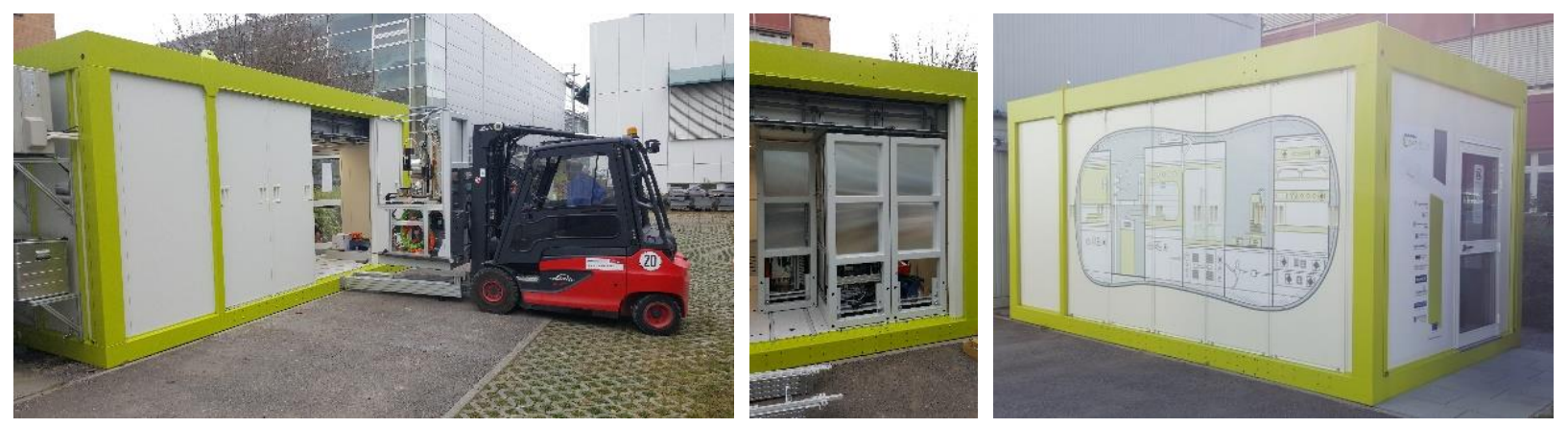

Figure 18: Implementation of process modules and configuration of the container-integrated production system

A welded steel frame supports the container for reinforcement purposes due to the interior installed masses and the 'weakened' sidewall required for PM installation. The reinforcement is needed to support the equipment during transport and operation as well as to reduce vibration during operation.

As described in the container and modular production system concept, the fully equipped control cabinet and server cabinets were integrated at the front-end inside the container. Furthermore, the air conditioning and filtration systems were installed and tested, successfully demonstrating cleanliness in line with ISO 14644-1 Class 6.

\subsection{Realization and Integration of Process Modules}

The first step towards the realization of the PMs was achieved by defining the available/required spaces and interfaces. An L-shaped steel frame was defined as being the base frame to facilitate the integration of single PM's within the container. An industrial mechatronic interface was defined to connect each PM in the same way to the container`s media infrastructure. 


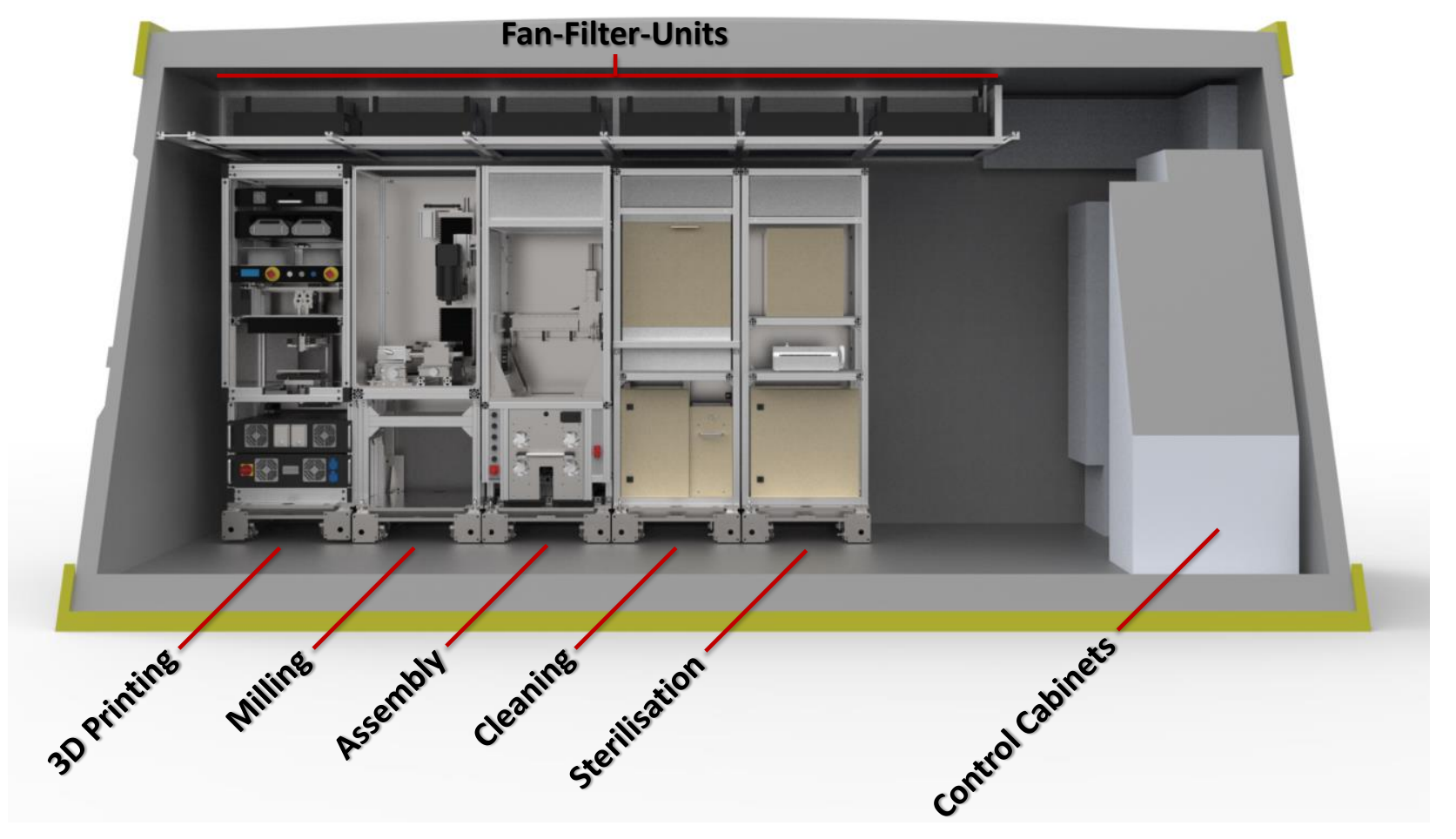

Figure 19: Mock-up rendering of process modules inside container

In total, five prototype PMs have been realized, as defined by the proposed process chain. This comprises one PM for AM, one for CNC milling, one for precise assembly operations, one cleaning module and one for sterilization equipment. A mock-up presentation of the process modules is shown in Figure 19. Additionally, an auxiliary process module for deionized water supply and drainage was setup and integrated. An overview of these PMs integrated within the container is shown in Figure 20.

For the AM module, thermoplastic material extrusion (ME) was selected as the most suitable Additive Manufacturing technique in relation to the prior determined requirements. The system has two print heads and is thus able to manufacture structures out of two different materials. Typically, this is a combination of a build material and a soluble support material. To assure the quality of the manufactured parts, the build process and its results are continuously monitored by a bespoke inprocess machine-vision based inspection system.

The milling module is based on a 5 -axis kinematic setup and has a working envelope of approximately $250 \times 250 \times 350 \mathrm{~mm}$. The milling module was developed specifically for the processing of free-formed 3D printed parts. Development initially started with a virtual model, which was then transferred into the physical realization of the PM.

Precise assembly is provided by the assembly module. The system is based on a 4-axis gantry setup and has a total repeatability of $<4 \mu \mathrm{m}$. Using a manual tool exchange interface, the system can be equipped with various tools and devices. For example, different grippers, dispensing systems or machine vision systems are available as functional modules that can be easily mounted to the module. 
The cleaning module allows for the removal of particles or other contaminants. It is realized by integrating an industrial cleaning machine into the module. The wet cleaning process is also used for support removal from AM components and the cleaning of all further parts.

The sterilization module integrates a steam based cleaning process and provides the equipment for appropriate packaging of the cleaned goods, and completed components/parts.
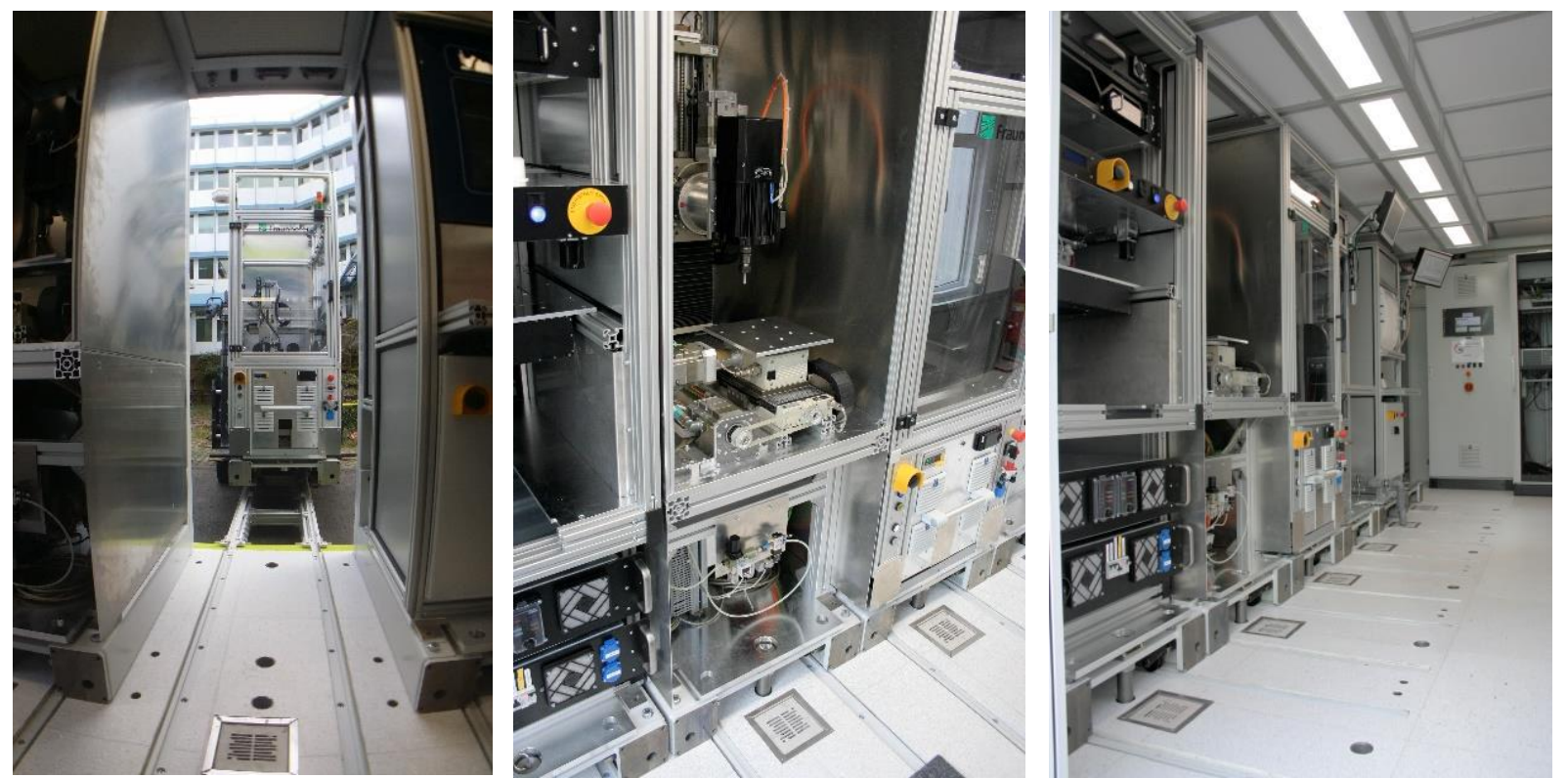

Figure 20: Process module integration (left), installed process modules (middle), view of equipment front and the operator's corridor (right).

An automated transfer system (e.g. conveyor belts or work piece carrier system) can be easily integrated within the established concept since the base plate level across the PMs working area are identical. The operator's corridor was considered to allow such implementation in the current configuration turning the mini-factory into an almost fully automated production system.

\subsection{Modular Control System and HMI}

For demonstration, all software tools enabling an easy configuration of the overall CassaMobile production system are run from the MainControl (MC). The $M C$ is the central system of the containerintegrated production system. Its primary function is to orchestrate the individual PMs via the ModuleViewer, which calls for the required specific input while offering each process module's capability via a recipe template. The following software tools are integrated and have been tested on the MC:

- The WorkflowManager (WFM)

- HMI/CAD-CAM backbone software

- CIMory

- ConfigManager

- Database for Workflows

- Container surveillance PLC 


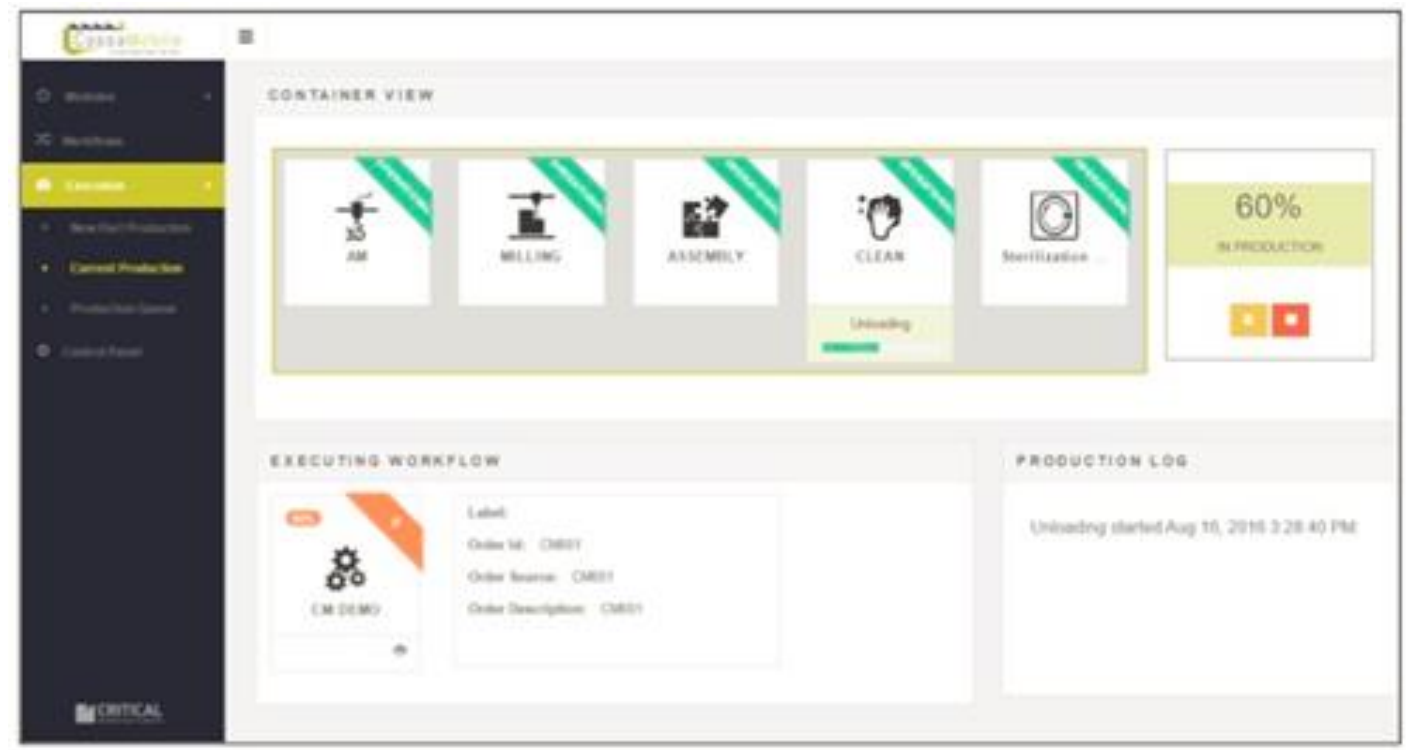

Figure 21: HMI workflow configuration panel

The network equipment consists primarily of the following hardware components:

- MainControl IPC

- VPN router for a worldwide easy and secured access to the productions system

- Access point for the use of mobile devices to support the prosumers

The $\mathrm{HMI}$ is a front desk application that is the multifunctional interface for all users of the production system. All necessary parameters and production steps can be controlled and modified via the HMI, as shown in Figure 21. The HMI software supports the user to reconfigure the manufacturing process flow. A specific focus was placed on establishing a Build Processor (BP) framework, which has been broadened to generate specific files for the PMs. A CAD/CAM converter tool was developed to provide the $\mathrm{HMI}$ and MainControl with specific CAM data for the PMs. The installed quality control and tracking function collects process parameters from the single PMs to create GMP- product documentation once the process chain has been completed.

Communication between the HMI and the WFM is performed by a set of SOAP interfaces that expose most of the WFM functionality so the WFM can be remotely controlled by the HMI. In the same way, the workflow database can be accessed. Additional to the SOAP interfaces, a set of real-time bi-directionally communicating channels were developed, implemented and tested in combination with the $\mathrm{HMI}$ software. These real-time communication channels were implemented with Signal- $R$, which uses permanently-opened web sockets to communicate data.

The integration of the HMI, CAD/CAM-backbone and MainControl was successfully realized and tested Highlights of the demonstrated Modular Control System and HMI include:

- A self-configuring 'plug \& produce' modular control system for an easy exchange and reconfiguration of the process chain 
- An easy to use human-machine interface which allows non-skilled operators (prosumers) the use of the container-integrated production system

- An intuitive process control and workflow management for high-quality products

- Quality control and monitoring functions for offline and in-process monitoring

\subsection{System Evaluation}

\subsubsection{System Configuration}

A module exchange was performed in order test the system configuration capabilities with the assembly module. The mechanical exchange of process modules can be realized within less than one hour, including re-establishing media and data connections. The configuration of the control system can be performed in less than 10 minutes. If this is extrapolated to six process modules, a complete reconfiguration can be realized in less than 8 hours, which corresponds to a typical working shift.

\subsubsection{Process Configuration and Execution}

A CAD model of the demonstration product was prepared and then uploaded to the HMI in STL format. The process chain was then configured in the HMI to a 3D printing, milling, assembly and cleaning process chain. G-Code for 3D printing, milling and assembly processes was generated automatically. The process was initiated using the HMI. The complete process chain was successfully executed without errors and all processes were performed within their specification limits. Transfer between the PM was carried out manually and start signals to the control system were provided via the HMI. All process steps were successfully documented using the track \& trace software within the main control system. The process flow of the manufacturing process is shown in Figure 22.

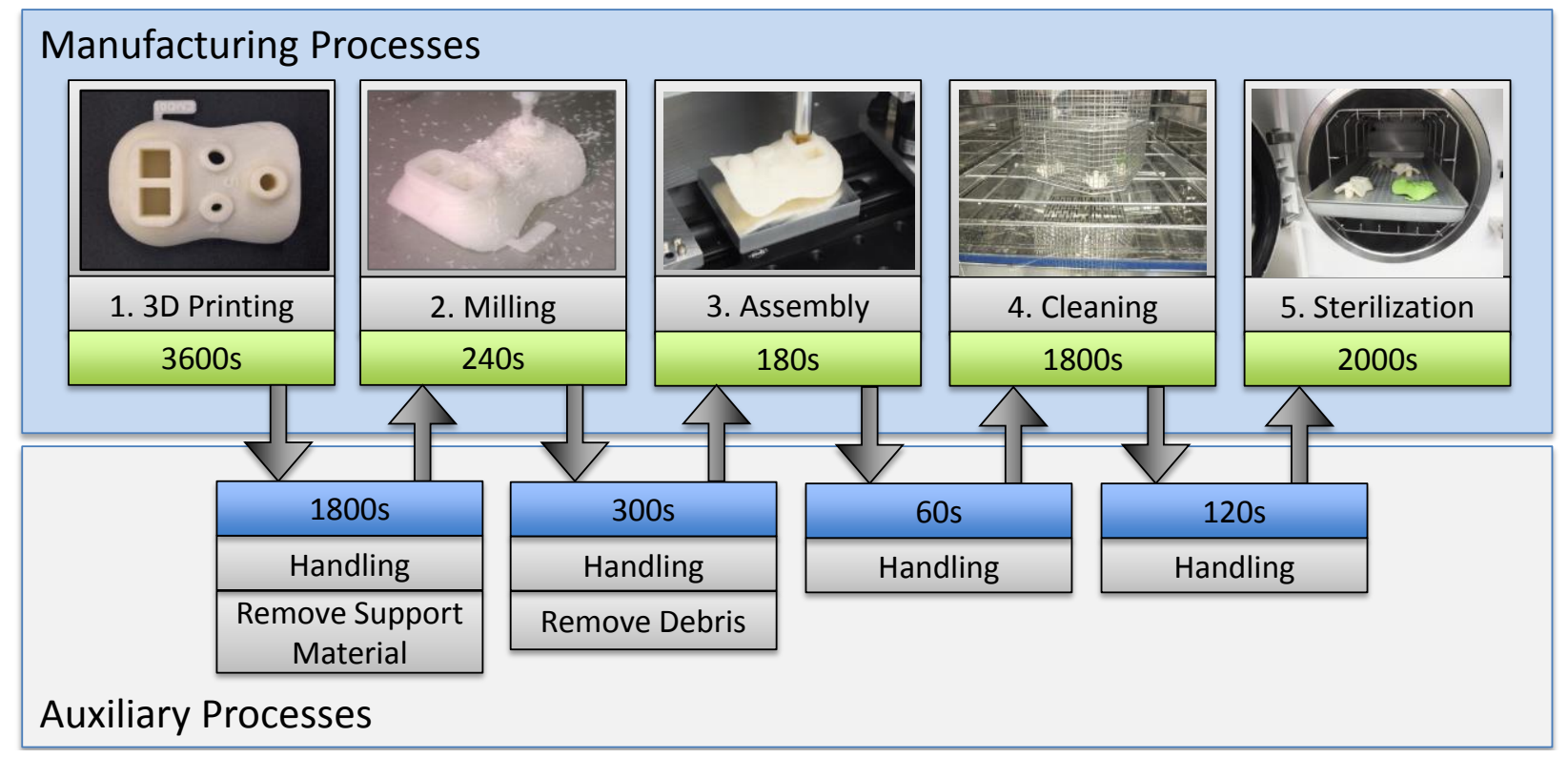

Figure 22: Manufacturing process of demonstration product

The total process duration is $10,100 \mathrm{~s}$, which corresponds to $168 \mathrm{~min}$. The demonstration product can therewith be realized rapidly with the proposed process chain. 


\subsubsection{Productivity and Unit Cost}

Based on the experimental realization of the serial process, the system productivity was examined. Cleaning and Sterilization are batch processes, while the other processes are serial processes. 3D printing can also be planned and executed as a batch process. The process duration then increases proportionally with the build volume. To calculate the throughput of the system the durations of the individual processes were summed. This was performed for batch sizes between 1 and 128. The resulting throughput is shown in Figure 23.

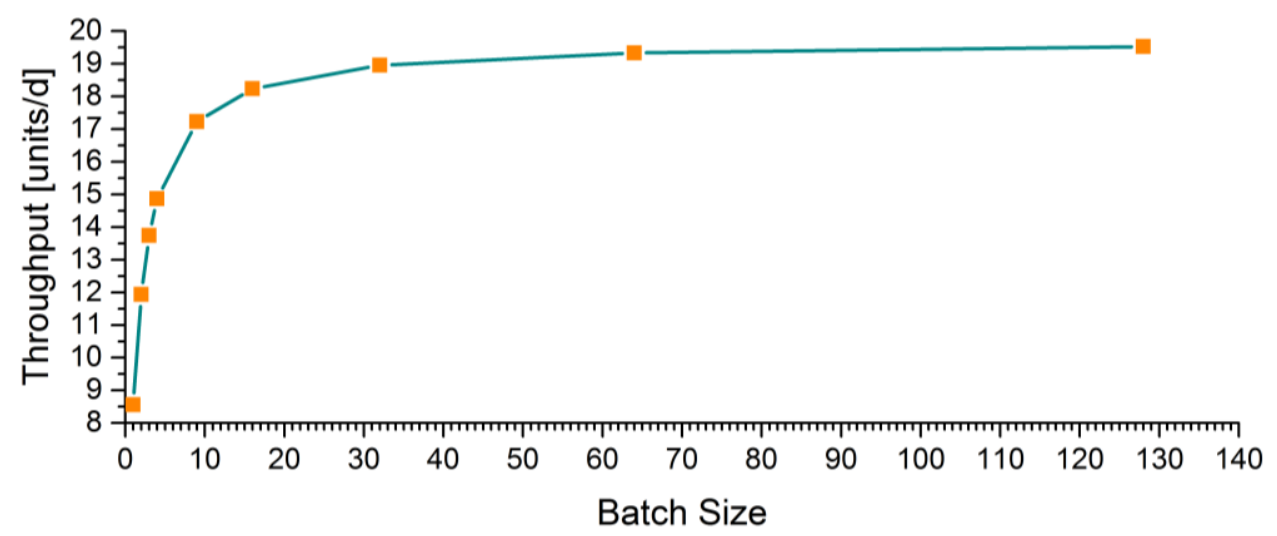

Figure 23: Throughput for different batch sizes

As the calculation results indicate, the throughput can be significantly increased by batch processing. For larger batch sizes $(\geq 32)$ a throughput of 19 units per day can be achieved, which corresponds to the required productivity.

With the productivity of the system known, a calculation of the unit cost was performed based on the method by Lindemann et al. [48]. Aim of the calculation was to assess if the system can be operated in an economically sustainable way. The method was slightly adapted to include the whole process chain and not only the AM process.

$\mathrm{C}_{\text {Build }}=\mathrm{C}_{\text {Fixed }}+\mathrm{R} \cdot \mathrm{T}_{\text {Build }}$

$\mathrm{C}_{\text {Build }} \quad$ Manufacturing cost for one unit in [€]

$C_{\text {Fixed }} \quad$ Fixed cost $[€]$

$\mathrm{R} \quad$ Machine Hourly Rate $[€ / \mathrm{h}]$

$\mathrm{T}_{\text {Build }} \quad$ Time required for the manufacturing process $[\mathrm{h}]$

The machine hourly rate $\mathrm{R}$ was calculated by taking investment and subsequent depreciation, maintenance, degree of utilization, labor cost and overhead into account. The fixed cost $C_{\text {Fixed }}$ was calculated by taking the material costs and auxiliary material costs into account. Fixed costs were calculated at $C_{\text {Fixed }}=1.13 €$. The hourly rate was calculated with $R=19.49 € / \mathrm{h}$. Unit costs were determined on the base of process durations for different batch sizes (Figure 24). 


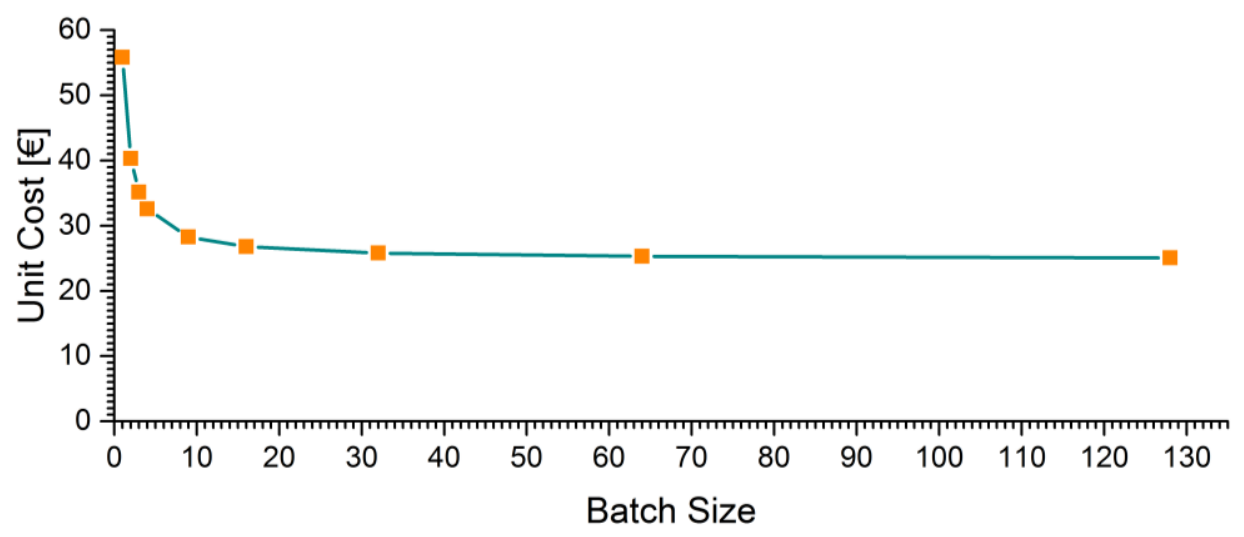

Figure 24: Unit manufacturing cost for different batch sizes

As expected, the unit cost for serial processing is higher than for batch processing. With increasing batch sizes, unit cost can be reduced by more than $50 \%$. Still, each unit can be individual regarding its shape, dimensions and assembly.

The calculated unit cost for the demonstrator part is acceptable for a low volume production and the initial target products. The unit costs determined here are roughly in line with cost calculations of AM processes found in the literature $[49,50]$, particularly when taking the additional cost from the container system and extended process chain into account.

Based on the calculations of the throughput and the unit cost, the proposed system is considered as comparable to existing Additive Manufacturing systems. According to Thomas and Gilbert a costeffective operation of Additive Manufacturing systems can be realized for small batches for both centralized and distributed production scenarios [50]. In this context, the presented results indicate that the proposed system can be principally operated in a cost-effective way. However, if the system can be operated in a sustainable manner depends eventually on the application and the business case.

\subsubsection{Business Model Considerations}

The consumer-centric business model of the 'factory on the go' is based on the attributes 'local availability' and 'individual product'. The challenge in the development of such production systems -as for every new system development - is given by its interfaces. As such, the scope was framed by the assumption to have the required infrastructure for the supply of media and material available at the place of installation. The research team was aware of creating a disruptive approach, which requirements for supply may not fit into today's supply chain structures. The future availability of digital tools for planning and consumer-integrated manufacturing orders legitimated the supposition to consider upstream and downstream business processes as steady factors for the business scenarios of this production facility development.

The attractiveness of an itinerant production facility is supported by the value of reduced lead times and reduced downstream logistic costs. While a strictly centralized organization has high coordination efforts decentralized organization suffer from inefficiencies due to lower workloads. The developed system can partly cover both disadvantages: the local supply of production services - self-configuring ('organizing') 
and high utilization ('efficiency') due to customized products at the required location. Figure $\mathbf{2 5}$ depicts the potential time savings by local installation to support existing productions and to create shortest time-to-market channels.

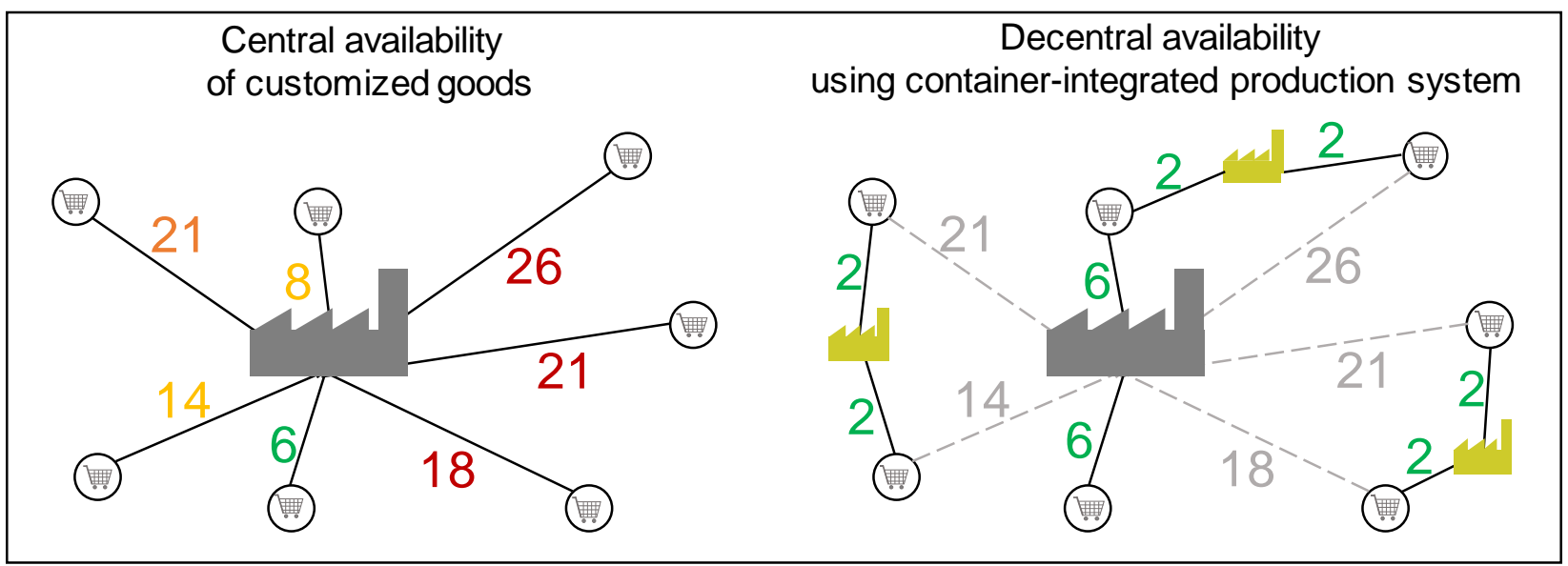

Figure 25: Exemplary downstream time savings for customized good supply using the containerintegrated factory on the go.

Potential business models for local production of custom products have been recently discussed by Matt et al. [5], Bogers et al. [28] and Piller et al. [51]. Strongly simplified, the business model must provide either a gain or solve a problem for a specified set customer profile. Additionally the business must also provide revenue, which is in this case achieved by selling the produced goods.

A potential value proposition for customers is the offering of custom high-quality components with low lead times. In this case it is assumed to primarily focus onto industrial companies as customers. A sample work-flow of a possible business process in presented in Figure 26. In a further assumption numerous CassaMobile systems are placed at remote locations.

It is aimed to offer the product with an online platform, where the customer may configure or design his product and may issue an order. This order is then processed centrally and the CassaMobile system closest to the customer is selected. The order is then issued to the selected CassaMobile, where the order is processed and the product is manufactured and then packaged. The finished product is then delivered or shipped to the customer.

This is one example of a possible business model. Other models may for example realize benefits for the customer by direct customer contact at the production container or by temporary leasing of CassaMobile systems in order to augment locally available production capacities. 


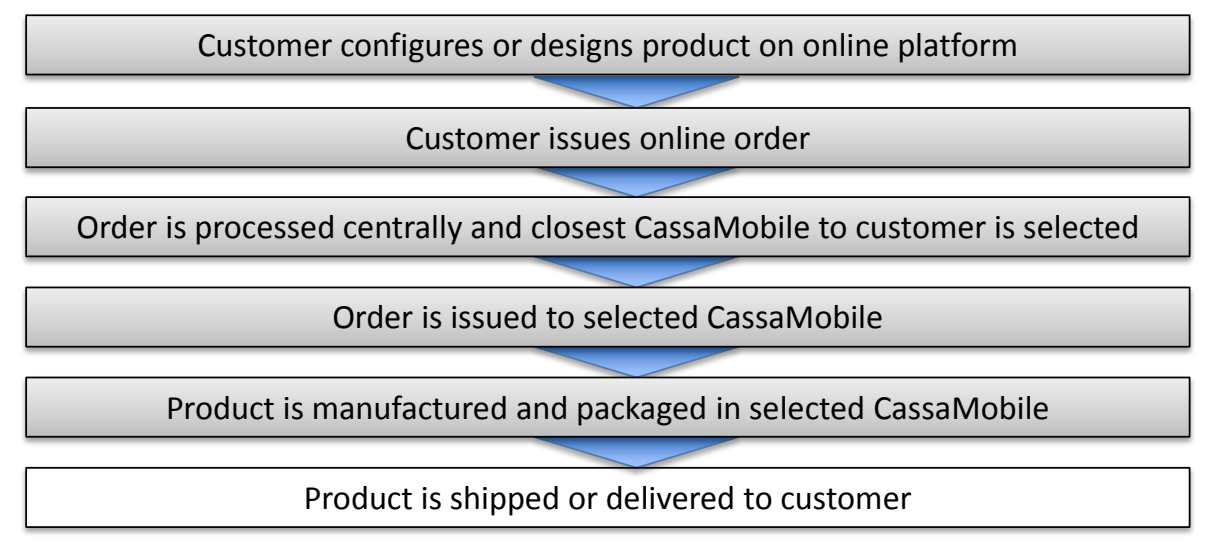

Figure 26: Possible business process work-flow

\subsubsection{Reduction of Lead Times}

As one of the main motivations of the proposed system is to reduce lead times of the ordered products, a calculation of the reduction potential has been performed. Within the assessment, a representative centralized scenario is compared to local production with a network of globally distributed CassaMobile systems. The centralized production is assumed to take place in Stuttgart, Germany. Local production is assumed to be performed in a catchment area of $50 \mathrm{~km}$, which corresponds to the extended area of a large town (e.g. Stuttgart). The time required for order entry, engineering and manufacturing of the produced good is assumed to be constant in all cases. Shipping time is assumed to be 6 hours for the local production case. For the centralized production case, the shipping times have been obtained from a representative parcel company [52]. The minimum and maximum lead times have been determined for each continent. The results are presented in Figure 27.

As can be seen from Figure 27, a potential reduction of lead times is to be expected for all cases. Local production would potentially be beneficial for countries with longer shipping times like e.g. Falkland Islands (6d) or Australia (4d), as well as countries where customs take several days (e.g. Cuba (7d) or Bolivia (5d)). Lead-time reduction potential is particularly beneficial for intercontinental orders. 


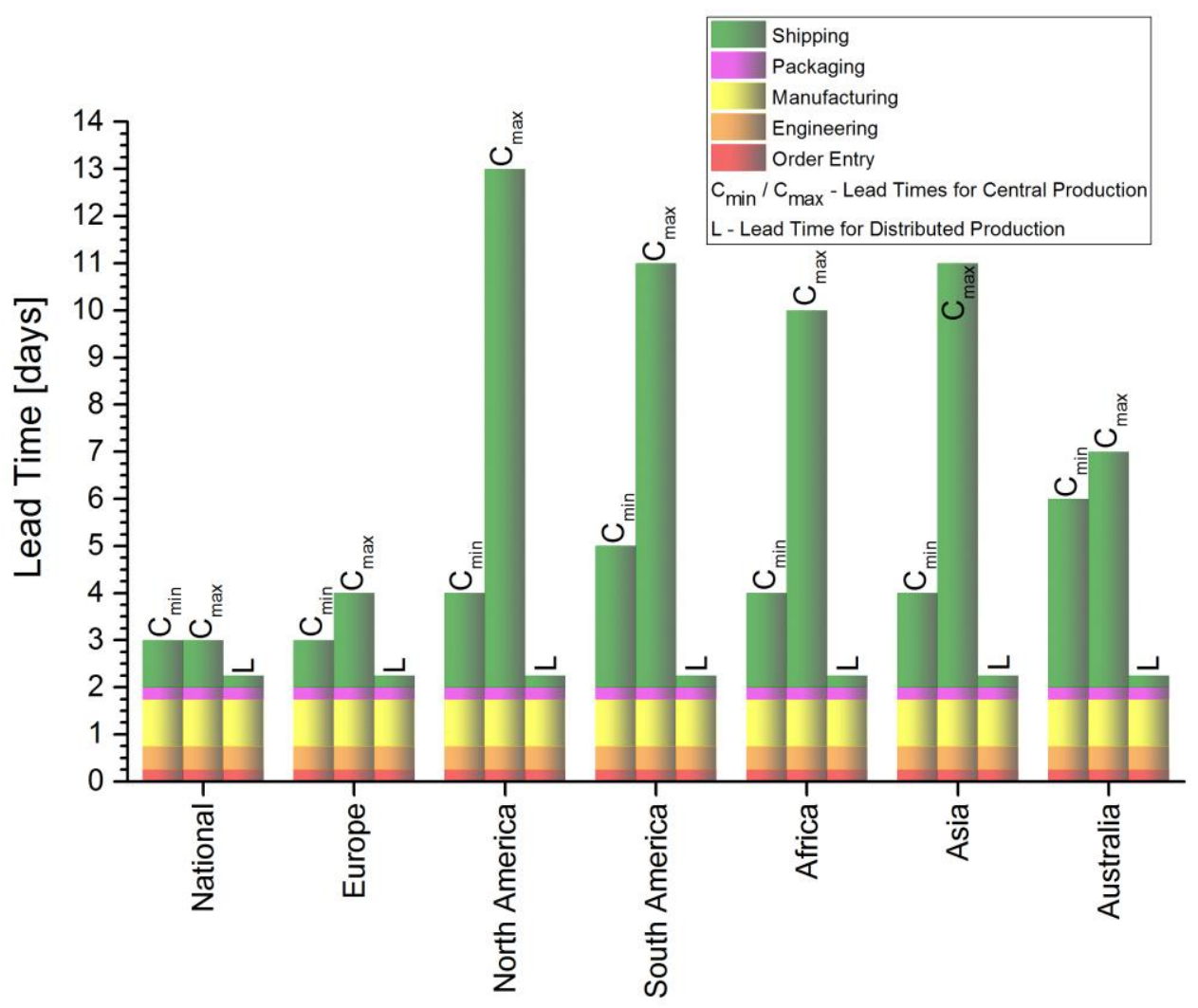

Figure 27: Lead times for central and local production scenarios per continent

Other advantages could be realized by the ability to rapidly respond to change. In cases where the supplied parts are insufficient in quantity, incorrect or in need of modification the advantages of local manufacture are emphasized and multiplied. The ability to arbitrarily alter batch size down (possibly to as low as one) could also have a big impact on lead time when centralized supply imposes fixed minimum batch sizes / order quantities.

\subsubsection{Discussion}

In Table 2, the fulfillment of the requirements is discussed. For a conclusive statement, further testing is necessary. The results presented in this paper are however promising and indicate further testing, preferably in an industrial environment.

Table 2: Fulfilment of requirements

\begin{tabular}{|l|l|}
\hline Requirement & Fulfilment \\
\hline $\begin{array}{l}\text { Rapid configuration and } \\
\text { deployment }\end{array}$ & $\begin{array}{l}\text { Rapid mechanical and control configuration supported by holistic } \\
\text { modular architecture. Rapid deployment demonstrated on prototype. }\end{array}$ \\
\hline $\begin{array}{l}\text { Easy transportation to the } \\
\text { point of need }\end{array}$ & $\begin{array}{l}\text { Container format minimizes the preparation effort for transportation } \\
\text { and can be easily transported throughout the world }\end{array}$ \\
\hline $\begin{array}{l}\text { Reliable operation at remote } \\
\text { locations }\end{array}$ & $\begin{array}{l}\text { The integration inside a container protects the system from outer } \\
\text { influences, as long the supply is provided. Remote controlled by WAN } \\
\text { interface is possible and enables continuous monitoring. }\end{array}$ \\
\hline Low volumes (5-20units/d) & System provides demanded throughput with applicable batch sizes \\
\hline
\end{tabular}




\begin{tabular}{|l|l|}
\hline $\begin{array}{l}\text { Highly individualized } \\
\text { products }\end{array}$ & $\begin{array}{l}\text { Each product may be individual regarding shape, dimensions, materials } \\
\text { and the components of the assembly due to AM processes and control } \\
\text { system }\end{array}$ \\
\hline Product quality & $\begin{array}{l}\text { Established processes are used, AM process is equipped with in-line } \\
\text { monitoring system to detect defects in situ. }\end{array}$ \\
\hline Process conditions critical & $\begin{array}{l}\text { Process condition controlled with sufficient cleanliness level, which can } \\
\text { be adapted according due to modular architecture. }\end{array}$ \\
\hline Track \& Trace required & $\begin{array}{l}\text { Track \& Trace implemented in control software using commercial } \\
\text { software package }\end{array}$ \\
\hline Operation by skilled worker & $\begin{array}{l}\text { System was successfully tested by technical person after short } \\
\text { introduction. }\end{array}$ \\
\hline System suitable for all three & $\begin{array}{l}\text { Generic product demonstrator was successfully manufactured with } \\
\text { respect to the required tolerances. Example parts for all regarded use } \\
\text { use cases have been successfully manufactured. }\end{array}$ \\
\hline Reduction of lead times & $\begin{array}{l}\text { Lead times can be substantially reduced by proposed approach, } \\
\text { particularly for international orders. }\end{array}$ \\
\hline Unit cost & $\begin{array}{l}\text { Unit cost is slightly higher, but still comparable to central production } \\
\text { scenarios. With respect to the regarded use case, the system can be } \\
\text { operated in a cost-effective way. }\end{array}$ \\
\hline
\end{tabular}

In the following Table 3, the proposed system is compared against state of the art systems, according to the prior determined criteria. Desktop or micro factory systems are stationary systems and are therefore hardly moveable. Truck- or van-based system and container factories are moveable, but do not offer reconfiguration functionality. Additionally, controlled process conditions are typically not integrated. Moveable factories are principally full-blown factories, and can therefore be realized with all required features. The size and necessary effort for the set-up is significantly higher, which impairs the transportability. Controlled process conditions can be principally implemented in all regarded solutions. The CassaMobile system integrates the reconfigurability from micro factories and combines it with the advantages of mobile factory systems.

Table 3: Comparison of the proposed system against the state of the art

\begin{tabular}{|c|c|c|c|c|c|c|}
\hline & 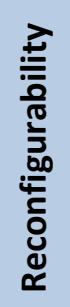 & 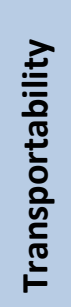 & 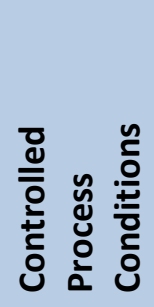 & 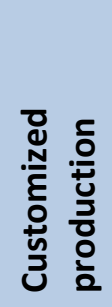 & 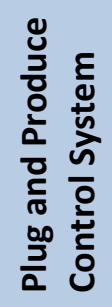 & 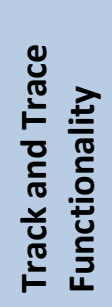 \\
\hline Desktop / Micro Factory & + & - & 0 & - & + & + \\
\hline Truck / Van Systems & - & + & 0 & + & - & - \\
\hline Container Factory & - & + & 0 & + & - & - \\
\hline Moveable Factories & - & o & o & o & 0 & 0 \\
\hline CassaMobile System & + & + & + & + & + & + \\
\hline
\end{tabular}




\section{Conclusions}

A reconfigurable and transportable production system is proposed as a container-integrated solution for the local production of highly customized products. The system provides the technical infrastructure for an operator or a prosumer to self-configure the system and to produce highly individual products at the right place and at the right time. For the first time, a reconfigurable and container-integrated manufacturing system with cleanroom capabilities has been realized. In contrast to existing approaches, e.g. the 'Factory-in-the-box' concept [25] or the mobile part hospital [21], a rapid exchange of process equipment and flexible adaption of cleanliness levels is possible from both mechanical and control systems.

A process chain is proposed, which combines an Additive Manufacturing process with CNC milling, assembly and cleaning processes. This combination allows overcoming the limitations of the individual processes, such as achievable precision or integration of functionality on customized parts. As a consequence, novel products may be developed in an integrative manner due to reduced restrictions by the production system and are to be specifically tailored to the process chain [53]. The processes and the proposed process modules support the economical realization of a customized production in a just-intime scenario. Comparable process chains have been proposed before $[54,55]$, but the integration into a transportable system has not been performed yet.

The process capabilities have been successfully demonstrated by a generic product demonstrator. A batch of 10 customized products has been produced using the whole process chain to prove the functionality of the entire production system and its affiliated sub-systems.

The local just-in-time production of individual products is particularly attractive for medical products. Due to thorough regulations, seamless tracking and documentation of the processes used is required for most medical products. This is supported by the quality tracking software as part of the container control software.

Now that the prototype system is available, testing with further applications will be carried out. Specifically, test runs for local just-in-time manufacturing of medical products will be continued to derive optimized requirements for the commercialization of the container-integrated production system.

Furthermore, the applicability of current and future business models will be analyzed for the optimization of the system's services. Using the current system, new business models can be tested in the field. As these are highly dependent on specific branches of products and services, further studies will be required to identify the marketability of established products and the accompanied reengineering needs for their remote and customized production.

\section{Acknowledgements}

The research leading to these results was performed within the CassaMobile project, which received funding from the European Union Seventh Framework Program under grant agreement 609146. More information about the project can be found on the project homepage (www.cassamobile.eu).

\section{References}


[1] R. Shah and P. T. Ward, "Lean manufacturing: context, practice bundles, and performance," Journal of operations management, vol. 21, pp. 129-149, 2003.

[2] R. Suri, It's about time: the competitive advantage of quick response manufacturing: CRC Press, 2016.

[3] R. Suri, Quick response manufacturing: a companywide approach to reducing lead times: CRC Press, 1998.

[4] K. Ueda, A. Lengyel, and I. Hatono, "Emergent synthesis approaches to control and planning in make to order manufacturing environments," CIRP Annals-Manufacturing Technology, vol. 53, pp. 385-388, 2004.

[5] D. T. Matt, E. Rauch, and P. Dallasega, "Trends towards Distributed Manufacturing Systems and modern forms for their design," Procedia CIRP, vol. 33, pp. 185-190, 2015.

[6] P. Renna, Production and Manufacturing System Management: Coordination Approaches and Multi-Site Planning: Coordination Approaches and Multi-Site Planning: IGI Global, 2012.

[7] G. Schuh, M. Bergholz, V. Liestmann, A. Merchiers, B. Sander, and J. Spille, "Modulare Dienstleistungen als Beitrag zur Flexibilisierung global verteilter Produktion," ZWF Zeitschrift für wirtschaftlichen Fabrikbetrieb, vol. 98, pp. 210-213, 2003.

[8] D. Wu, J. L. Thames, D. W. Rosen, and D. Schaefer, "Towards a cloud-based design and manufacturing paradigm: looking backward, looking forward," in Proceedings of the ASME 2012 International Design Engineering Technical Conference \& Computers and Information in Engineering Conference IDETC/CIE, 2012, p. 18.

[9] I. J. Petrick and T. W. Simpson, "3D printing disrupts manufacturing: how economies of one create new rules of competition," Research-Technology Management, vol. 56, pp. 12-16, 2013.

[10] Y. Koren, U. Heisel, F. Jovane, T. Moriwaki, G. Pritschow, G. Ulsoy, and H. Van Brussel, "Reconfigurable manufacturing systems," CIRP Annals-Manufacturing Technology, vol. 48, pp. 527-540, 1999.

[11] H. A. ElMaraghy, "Flexible and reconfigurable manufacturing systems paradigms," International journal of flexible manufacturing systems, vol. 17, pp. 261-276, 2005.

[12] M. G. Mehrabi, A. G. Ulsoy, and Y. Koren, "Reconfigurable manufacturing systems: Key to future manufacturing," Journal of Intelligent manufacturing, vol. 11, pp. 403-419, 2000.

[13] V. Marík, J. M. Lastra, and P. Skobelev, "Industrial applications of holonic and multi-agent systems," in 6th International Conference, HoloMAS 2013, Prague, Czech Republic, August 2013, Proceedings, Lecture Notes in Artificial Intelligence 8062, Subseries of Lecture Notes in Computer Science, 2000.

[14] J. Barata and L. M. Camarinha-Matos, "Coalitions of manufacturing components for shop floor agility-the CoBASA architecture," International journal of networking and virtual organisations, vol. 2, pp. 50-77, 2003.

[15] Y. Koren and M. Shpitalni, "Design of reconfigurable manufacturing systems," Journal of manufacturing systems, vol. 29, pp. 130-141, 2010.

[16] A.-L. Andersen, K. Nielsen, and T. D. Brunoe, "Prerequisites and barriers for the development of reconfigurable manufacturing systems for high speed ramp-up," Procedia CIRP, vol. 51, pp. 7-12, 2016.

[17] S. Fox, "Moveable factories: How to enable sustainable widespread manufacturing by local people in regions without manufacturing skills and infrastructure," Technology in Society, vol. 42, pp. 49-60, 2015.

[18] A. Postawa, M. Siewert, and G. Seliger, "Mini factories for cocoa paste production," in Sustainable Manufacturing, ed: Springer, 2012, pp. 175-181.

[19] Y. Um, S. Oh, J. Lee, S. Kim, and Y. Jang, "The development of container-type plant factory and growth of leafy vegetables as affected by different light sources," Journal of Bio-Environment Control, 2010. 
[20] (2009, 2016-09-15). Defense Industry Daily - The US Army's Mobile Parts Hospitals.

[21] S. Barkley. (2009, 2016-09-15). Mobile Parts Hospitals resuscitate broken gear.

[22] H. M. Odom, M. Aldaghi, R. Anderson, M. Lopez, and M. Pearse, "CONTROLLED ENVIRONMENT FOR PLANT PRODUCTION," 2016.

[23] R. Tuokko, "Desktop Factories-Actual Knowledge Status and Experiences from Far East," in Manufuture 2011 conference, October, 2011, p. 2011.

[24] E. Järvenpää, R. Heikkilä, and R. Tuokko, "2.5 TUT-microfactory-a small-size, modular and sustainable production system," interface, vol. 20, p. 30cm, 2013.

[25] M. Jackson and A. Zaman, "Factory-in-a-box-mobile production capacity on demand," International Journal of Modern Engineering, vol. 8, pp. 12-26, 2007.

[26] M. Onori, J. Barata, and R. Frei, "Evolvable assembly systems basic principles," Information Technology for Balanced Manufacturing Systems, vol. 220, p. 500, 2006.

[27] V. Stich, S. Kompa, C. Meier, and C. M. Senger, "Changeable production systems in the machinery and equipment industry-Success factors: It-integration and real-time capable production planning and control," in Concurrent Enterprising (ICE), 2011 17th International Conference on, 2011, pp. 1-8.

[28] M. Bogers, R. Hadar, and A. Bilberg, "Additive manufacturing for consumer-centric business models: Implications for supply chains in consumer goods manufacturing," Technological forecasting and social change, vol. 102, pp. 225-239, 2016.

[29] A. Toffler and T. Alvin, The third wave: Bantam books New York, 1981.

[30] R. Cohen and G. Khermouch, "What Happens When Consumers Turn into Prosumers?," The Electricity Journal, vol. 25, pp. 3-4, 2012.

[31] S. Fox and L. Li, "Expanding the scope of prosumption: A framework for analysing potential contributions from advances in materials technologies," Technological forecasting and social change, vol. 79, pp. 721-733, 2012.

[32] D. Chen, S. Heyer, S. Ibbotson, K. Salonitis, J. G. Steingrímsson, and S. Thiede, "Direct digital manufacturing: definition, evolution, and sustainability implications," Journal of Cleaner Production, vol. 107, pp. 615-625, 2015.

[33] T. Bauernhansl, "Die Vierte Industrielle Revolution - Der Weg in ein wertschaffendes Produktionsparadigma," in Industrie 4.0 in Produktion, Automatisierung und Logistik, ed: Springer, 2014, pp. 5-35.

[34] G. Schuh, T. Potente, and A. Hauptvogel, "Methodology for the evaluation of forecast reliability of production planning systems," Procedia CIRP, vol. 17, pp. 469-474, 2014.

[35] D. E. H. Warnecke, "Fractal Company-A Revolution in Corporate Culture," in Manufacturing Technologies for Machines of the Future, ed: Springer, 2003, pp. 63-85.

[36] T. Bauernhansl, F. Müller, M. Bressner, D. Görzig, and T. Röber, Industrie 4.0 - Entwicklungsfelder für den Mittelstand. Stuttgart: Fraunhofer IPA, 2016.

[37] R. Thoben, Parallelroboter für die automatisierte Mikromontage: VDI-Verlag, 1999.

[38] R. Adamietz, T. Iseringhausen, S. Gerstenberg, and A. Verl, "A First Step towards Cross-Platform Integration in Modular Micro-assembly Systems-Concept for a Process Module Construction Kit," presented at the Conference on Changeable, Agile, Reconfigurable and Virtual Production (CARV 2013), München, 2013.

[39] S. Scheifele, A. Lechler, and A. Verl, "Automated Online Control System Configuration," presented at the FAIM 2015, Wolverhampton, UK, 2015.

[40] S. Scheifele and A. Verl, "Automated Control System Generation Out of the Virtual Machine," Procedia Technology, vol. 26, pp. 349-356, 2016.

[41] C. Kircher, M. Seyfarth, K. Wurst, and G. Pritschow, "Self-adapting control systems for RMS," in CIRP 3rd international conference on reconfigurable manufacturing, Ann Arbor, 2005. 
[42] M. Peschl, N. Link, M. Hoffmeister, G. Gonçalves, and F. L. Almeida, "Designing and implementation of an intelligent manufacturing system," Journal of Industrial Engineering and Management, vol. 4, pp. 718-745, 2011.

[43] J. Friedrich, S. Scheifele, A. Verl, and A. Lechler, "Flexible and Modular Control and Manufacturing System," Procedia CIRP, vol. 33, pp. 115-120, 2015.

[44] N. G. Odrey and G. Mejia, "A re-configurable multi-agent system architecture for error recovery in production systems," Robotics and Computer-Integrated Manufacturing, vol. 19, pp. 35-43, Feb-Apr 2003.

[45] J. C. Hernandez-Matias, A. Vizan, J. Perez-Garcia, and J. Rios, "An integrated modelling framework to support manufacturing system diagnosis for continuous improvement," Robotics and Computer-Integrated Manufacturing, vol. 24, pp. 187-199, Apr 2008.

[46] L. Gail, U. Gommel, and H.-P. Hortig, Reinraumtechnik: Springer DE, 2012.

[47] U. Gommel, F. Bürger, and M. Keller, "Cleanroom and Cleanliness suitability-definitions, test methods and assessment," Lothar Gail, Udo Gommel and Hans-Peter Hortig. Reinraumtechnik. Berlin, Heidelberg: Springer Verlag, 2011.

[48] C. Lindemann, U. Jahnke, M. Moi, and R. Koch, "Analyzing Product Lifecycle Costs for a Better Understanding of Cost Drivers in Additive Manufacturing," presented at the 23th Annual International Solid Freeform Fabrication Symposium-An Additive Manufacturing Conference, Austin, Texas, USA, 2012.

[49] N. Hopkinson and P. Dickens, "Analysis of Rapid Manufacturing - Using Layer Manufacturing Processes for Production," Journal of Mechanical Engineering Science vol. 217, pp. 31-39, 2003.

[50] D. S. Thomas and S. W. Gilbert, Costs and cost effectiveness of additive manufacturing. Gaithersburg, USA: National Institute of Standards and Technology, 2014.

[51] F. T. Piller, C. Weller, and R. Kleer, "Business models with additive manufacturing-opportunities and challenges from the perspective of economics and management," in Advances in Production Technology, ed: Springer, 2015, pp. 39-48.

[52] "Die DHL Express Welt - Ziele, Zeiten, Preise 2017," ed. Bonn, Germany: DHL Express Germany $\mathrm{GmbH}, 2017$.

[53] J. Gausemeier, R. Dumitrescu, S. Kahl, and D. Nordsiek, "Integrative development of product and production system for mechatronic products," Robotics and Computer-Integrated Manufacturing, vol. 27, pp. 772-778, Aug 2011.

[54] S. Scholz, T. Mueller, M. Plasch, H. Limbeck, R. Adamietz, T. Iseringhausen, D. Kimmig, M. Dickerhof, and C. Woegerer, "A modular flexible scalable and reconfigurable system for manufacturing of Microsystems based on additive manufacturing and e-printing," Robotics and Computer-Integrated Manufacturing, vol. 40, pp. 14-23, 2016.

[55] J. Guenthel, D. Holzinger, R. Birch, and O. Refle, "Process and Machine Development for the Inegration of Conductive Path Inside a 3D Printed Microsystem," presented at the Proc. Direct Digital Manufacturing Conference, Berlin, Germany, 2016. 